\title{
Origin of High Temperature Oxidation Resistance of Ti-Al-Ta-N Coatings
}

\author{
R. Hollerweger ${ }^{1}$, H. Riedl ${ }^{1}$, J. Paulitsch ${ }^{2}$, M. Arndt ${ }^{3}$, R. Rachbauer ${ }^{3}$, P. Polcik ${ }^{4}$, S. Primig ${ }^{5}$, P. \\ H. Mayrhofer ${ }^{1,2}$
}

${ }^{1}$ Christian Doppler Laboratory for Application Oriented Coating Development at the Institute of Materials Science and Technology, Vienna University of Technology, 1040 Vienna, Austria

${ }^{2}$ Institute of Materials Science and Technology, Vienna University of Technology, 1040 Vienna, Austria

${ }^{3}$ Oerlikon Balzers Coating AG, 9469 Balzers, Principality of Liechtenstein

${ }^{4}$ Plansee Composite Materials GmbH, 86983 Lechbruck am See, Germany

${ }^{5}$ Department of Physical Metallurgy and Materials Testing Montanuniversität Leoben, A-8700 Leoben, Austria

\section{Abstract}

Alloying Ti-Al-N coatings with Ta has proven to enhance their hardness, thermal stability, and oxidation resistance. However, especially for arc-evaporated Ti-Al-Ta-N coatings only limited information on the detailed influence of the elements on various properties is available. Therefore, we have developed arc-evaporated $\mathrm{Ti}_{1-x-y} \mathrm{Al}_{x} \mathrm{Ta}_{y} \mathrm{~N}$ coatings with various $\mathrm{Al}(\mathrm{x}=0.50-0.65)$ and $\mathrm{Ta}(\mathrm{y}=0.00-0.15)$ contents. While the thermal stability of our coatings during annealing in inert He atmosphere increases with increasing Ta content, best results are obtained for specific Ta-Al ratios during oxidation. Single phase cubic $\mathrm{Ti}_{0.32} \mathrm{Al}_{0.60} \mathrm{Ta}_{0.08} \mathrm{~N}$ yields a mass-gain of only $\sim 5 \%$ after $5 \mathrm{~h}$ at $950{ }^{\circ} \mathrm{C}$ in synthetic air, whereas $\mathrm{Ti}_{0.35} \mathrm{Al}_{0.65} \mathrm{~N}$ is completely oxidized after $15 \mathrm{~min}$. This is in part based on the 
suppressed anatase and direct rutile $\mathrm{TiO}_{2}$ formation at a defined Ta-Al content. Consequently, the anatase-to-rutile transformation, generally observed for $\mathrm{Ti}_{1-x} \mathrm{Al}_{x} \mathrm{~N}$, is absent. This reduces the generation of pores and cracks within the oxide scale and especially at the nitride-oxide interface, leading to the formation of a protective rutile and corundum based oxide scale. This is also reflected in the pronounced decrease in activation energy for the protective scale formation from $232 \mathrm{~kJ} / \mathrm{mol}$ for $\mathrm{Ti}_{0.35} \mathrm{Al}_{0.65} \mathrm{~N}$ down to $14.5 \mathrm{~kJ} / \mathrm{mol}$ for $\mathrm{Ti}_{0.32} \mathrm{Al}_{0.60} \mathrm{Ta}_{0.08} \mathrm{~N}$. Based on our results we can conclude that especially phase transformations within the oxide scale need to be suppressed, as the connected volume changes lead to the formation of cracks and pores.

\section{Keywords}

TiAITaN, AITiN, anatase, rutile, oxidation kinetics

\section{Introduction}

The development of hard protective coatings with increased thermal stability and oxidation resistance is in the main focus of several investigations [1-4]. Transition metal nitrides like TiN were one of the first industrially applied hard coatings. Even though TiN exhibits an excellent thermal stability, its mechanical properties at high temperatures as well as its oxidation resistance at temperatures higher than $500{ }^{\circ} \mathrm{C}$ is limited. Therefore, Münz [5] proposed to alloy TiN with aluminum to form a ternary $\mathrm{Ti}_{1-x} \mathrm{Al}_{x} \mathrm{~N}$ and thus to 
enhance its mechanical properties and oxidation resistance and hence to increase the lifetime of a protected tool.

As industrial demands on cutting inserts, mills and drills are continuously increasing, a further optimization of such protective coatings is necessary. Critical prerequisites are the phase stability of the nitride coating itself and a good oxidation resistance. Depending on the $\mathrm{Al}$ content, the supersaturated $\mathrm{Ti}_{1-\mathrm{x}-\mathrm{y}} \mathrm{Al}_{x} \mathrm{~N}$ phase starts to decompose at around 800 ${ }^{\circ} \mathrm{C}$ into isostructural face centered cubic (fcc) TiN and fcc-AIN. The latter is a metastable (high pressure) phase of AIN, which further transforms into hexagonal close packed (hcp, wurtzite type) AIN with a pronounced volume increase of $\sim 24 \%[6,7]$. The thereby obtained dual phase structure (fcc-TiN and hcp-AIN) of the coating and the possibly generated micro-cracks not just result in a massive mechanical attack of the coating itself, but also leads to the formation of additional diffusion paths, decreasing the oxidation resistance $[1,8,9]$. Therefore, Holec et al. [10,11], Rachbauer et al. [12-15], and several other authors [16-22] have intensely studied the effect of trivalent, tetravalent and pentavalent alloying elements $(\mathrm{X})$ on the thermal stability of sputter deposited $\mathrm{Ti}_{1-\mathrm{x}-}$ ${ }_{y} \mathrm{Al}_{\mathrm{x}} \mathrm{X}_{\mathrm{y}} \mathrm{N}$ coatings. These investigations showed that especially Ta (a pentavalent element) results in a pronounced increase in thermal stability of $\mathrm{Ti}_{1-x-y} \mathrm{Al}_{x} \mathrm{X}_{\mathrm{y}} \mathrm{N}$ by shifting the onset of the nitride phase decomposition by $\sim 200{ }^{\circ} \mathrm{C}$ to higher temperatures. The main reason for the increased thermal stability is based on the reduced chemical driving force for decomposition and retarded decomposition processes with increasing Ta content [11]. Additionally, alloying $\mathrm{Ta}$ to $\mathrm{Ti}_{1-x} \mathrm{Al}_{x} \mathrm{~N}$ is also very beneficial for increasing the oxidation 
resistance [15]. The increased oxidation resistance can only partly be understood by the reduced oxygen defects within rutile $\mathrm{TiO}_{2}$ through alloying with pentavalent $\mathrm{Ta}$ [23], and the suggested promotion of corundum type $\mathrm{Al}_{2} \mathrm{O}_{3}$ formation $[24,25]$.

Therefore, this study focuses on the thermal stability and oxidation resistance of arc evaporated $\mathrm{Ti}_{1-\mathrm{x}-\mathrm{A}} \mathrm{Al}_{\mathrm{x}} \mathrm{Ta}_{\mathrm{y}} \mathrm{N}$ protective coatings and especially on the influence of $\mathrm{Al}$ and $\mathrm{Ta}$ concentrations on the oxide scale formation.

\section{Experimental}

$\mathrm{Ti}_{1-\mathrm{x}-\mathrm{A}} \mathrm{Al}_{\mathrm{x}} \mathrm{Ta}_{\mathrm{y}} \mathrm{N}$ coatings (thickness $\sim 3 \mu \mathrm{m}$ ) with six different compositions were reactively deposited in an industrial scale Balzers INNOVA arc evaporation plant using a target current of $150 \mathrm{~A}$, a bias potential of $-80 \mathrm{~V}$, a substrate temperature of $500{ }^{\circ} \mathrm{C}$ and a nitrogen pressure of 3.5 Pa. The Prior to the depositions on various substrates (alumina (99.7\% $\left.\mathrm{Al}_{2} \mathrm{O}_{3}\right)$, silicon (100), iron foil, austenite, and high speed steel), an argon ion etching step was used to further clean the substrate surfaces allowing for increased coating adherence. The depositions were conducted with $\mathrm{Ti}_{0.50} \mathrm{Al}_{0.50}, \mathrm{Ti}_{0.475} \mathrm{Al}_{0.475} \mathrm{Ta}_{0.05}$, $\mathrm{Ti}_{0.45} \mathrm{Al}_{0.45} \mathrm{Ta}_{0.10}, \mathrm{Ti}_{0.34} \mathrm{Al}_{0.66}, \mathrm{Ti}_{0.323} \mathrm{Al}_{0.627} \mathrm{Ta}_{0.05}$, or $\mathrm{Ti}_{0.306} \mathrm{Al}_{0.594} \mathrm{Ta}_{0.10}$ targets, which were powder metallurgically formed from single element Al, $\mathrm{Ti}$, Ta metal powders (final density higher than $99 \%)$.

Structural investigations were performed with a PANalytical X'pert X-Ray diffractometer (XRD) in Bragg Brentano geometry with CuKa radiation. Cross-sectional micrographs 
were obtained by a FEI Quanta 200 field emission gun (FEG) scanning electron microscope (SEM). The attached EDAX Pegasus XM4 energy dispersive X-ray (EDX) detector was used for evaluating the chemical composition. Differential scanning calorimetry (DSC) combined with thermo-gravimetric analysis (TGA) measurements were performed in a SETSYS Evolution 2400 DSC using a heating rate of $20 \mathrm{~K} / \mathrm{min}, 50 \mathrm{sccm} \mathrm{He}$ flow, and a maximum temperature of $1600{ }^{\circ} \mathrm{C}$. Isothermal DSC and TGA oxidation investigations were performed at 850 and $950{ }^{\circ} \mathrm{C}$. Therefore, the samples were heated with $50 \mathrm{~K} / \mathrm{min}$ in Helium and kept for $20 \mathrm{~min}$ at the respective temperature. Subsequently, the oxidation step was initiated by exchanging the He atmosphere with synthetic air ( 20.5 vol\% $\mathrm{O}_{2}, 79.5$ vol\% $\mathrm{N}_{2}$ ). After $5 \mathrm{~h}$ of oxidation, the samples were cooled down to room temperature with a cooling rate of $50 \mathrm{~K} / \mathrm{min}$. To investigate the oxide phase evolution with progressing oxidation time additional DSC-TGA oxidation measurements were performed for selected samples and specific treatment durations. To avoid substrate interference during DSC-TGA measurements the coatings were chemically removed (diluted nitric acid) from their iron foils. Prior and after these DSCTGA measurements the coating materials were analyzed by XRD. Additionally to the TGA signal during oxidation, we have measured the weight of our samples before and after the oxidation treatment by an external high precision balance. This data was used for calculating the fraction of consumed nitride material (see chapter 3.2, Table 1). 
Ambient air oxidation treatments of coated alumina samples were performed at 850 and $950{ }^{\circ} \mathrm{C}$ for $20 \mathrm{~h}$. SEM fracture cross sectional micrographs of these samples were used for discussing the morphology of the respective oxide scale.

\section{Results}

The chemical compositions of our arc-evaporated coatings, normalized to a nitrogen content of $50 \%$, are $\mathrm{Ti}_{0.51} \mathrm{Al}_{0.49} \mathrm{~N}, \quad \mathrm{Ti}_{0.47} \mathrm{Al}_{0.45} \mathrm{Ta}_{0.08} \mathrm{~N}, \quad \mathrm{Ti}_{0.43} \mathrm{Al}_{0.42} \mathrm{Ta}_{0.15} \mathrm{~N}, \quad \mathrm{Ti}_{0.35} \mathrm{Al}_{0.65} \mathrm{~N}$, $\mathrm{Ti}_{0.32} \mathrm{Al}_{0.60} \mathrm{Ta}_{0.08} \mathrm{~N}$ and $\mathrm{Ti}_{0.30} \mathrm{Al}_{0.54} \mathrm{Ta}_{0.16} \mathrm{~N}$. Two general trends can be observed when relating the coating compositions to the used target compositions. The Al content is always below and the Ta content significantly above ( $50 \%)$ the target composition. This can be explained by the high mass-difference between $\mathrm{Al}$ and $\mathrm{Ta}$ and hence Al could be significantly more scattered in the gas phase or resputtered from the growing film. Figure 1 shows fracture cross sectional micrographs of reactively arc evaporated Al rich (Al/(Al+Ti) 0.65) $\mathrm{Ti}_{1-x-y} \mathrm{Al}_{\mathrm{x}} \mathrm{Ta}_{\mathrm{y}} \mathrm{N}$ coatings on high speed steel with Ta contents of $\mathrm{y}=0$, 0.08 , and 0.16 , Fig. 1a-c. These images are representative for all investigated coatings and exhibit a dense and fine columnar structure. The corresponding XRD patterns, Figs. 2a and $b$, for medium and high Al contents, respectively, indicate a single phase face centered cubic B1 structure for all Ta contents. The crystallite size (evaluated with a quadratic Williamson Hall plot) is around $20 \mathrm{~nm}$ and slightly decreases with increasing tantalum content. According to a linear interpolation between the lattice parameters of fcc-TiN and fcc-AIN, as suggested by Vegard for highly ionic crystals [26] and hence not 
for such materials, the XRD peak positions for fcc- $\mathrm{Ti}_{0.51} \mathrm{Al}_{0.49} \mathrm{~N}$ should be in the middle between fcc-TiN and fcc-AIN. Deviations from these XRD positions are due to the positive deviations from Vegard's estimation as studied by Density Functional Theory (DFT) in Refs. $[10,27]$ and due to the physical vapor deposition process generated structural defects leading to micro-strains. With increasing tantalum content $\left(\mathrm{Ti}_{0.47} \mathrm{Al}_{0.45} \mathrm{Ta}_{0.08} \mathrm{~N}\right.$ and $\mathrm{Ti}_{0.43} \mathrm{Al}_{0.42} \mathrm{Ta}_{0.15} \mathrm{~N}$ ) clear peak shifts to lower diffraction angles (towards fcc-TaN) suggest for a solid solution of Ta to the metal sublattice. A corresponding behavior can be observed for our $\mathrm{Al}$ rich coatings with compositions of $\mathrm{Ti}_{0.35} \mathrm{Al}_{0.65} \mathrm{~N}, \mathrm{Ti}_{0.32} \mathrm{Al}_{0.60} \mathrm{Ta}_{0.08} \mathrm{~N}$, and $\mathrm{Ti}_{0.30} \mathrm{Al}_{0.54} \mathrm{Ta}_{0.16} \mathrm{~N}$, Fig. 2b.

\subsection{Thermal stability}

Differential scanning calorimetry of our samples clearly exhibit pronounced exothermic features in the temperature range $500-1300{ }^{\circ} \mathrm{C}$, see Fig. 3. The broad exothermic feature between 500 and $1000^{\circ} \mathrm{C}$ is the sum of several exothermic reactions like recovery effects (annihilation or rearrangement of defects to lower energy sites) and especially the decomposition of the supersaturated fcc- $\mathrm{Ti}_{1-x-y} \mathrm{Al}_{x} \mathrm{Ta}_{y} \mathrm{~N}$ phase to isostructural Ti rich and $\mathrm{Al}$ rich cubic domains, see Refs. $[28,29]$ for more details. The main exothermic features with peak temperatures between 1000 and $1200{ }^{\circ} \mathrm{C}$ can be assigned to the phase transformation of the fcc Al rich cubic domains (or even fcc-AIN) into hcp-AIN. The massive volume expansion of $\sim 24 \%$ of this transformation $[7,30]$ can lead to a disintegration of the coatings and increased crack network. Most likely this is also the 
reason for the often-observed connected mass-reduction, due to $\mathrm{N}_{2}$-release driven by available diffusion pathways. The peak-temperatures of the described DSC feature increases from 1100 to 1200 to $1250{ }^{\circ} \mathrm{C}$ for the medium Al containing coatings with increasing Ta content. Correspondingly, also their mass-loss is shifted to higher temperatures from $\sim 1200$ to $1300{ }^{\circ} \mathrm{C}$, see Fig. 3a. Whereas TGA suggest that the massloss of $\mathrm{Ti}_{0.51} \mathrm{Al}_{0.49} \mathrm{~N}$ is finished after a loss of $\sim 2 \%$, the Ta containing coatings $\mathrm{Ti}_{0.47} \mathrm{Al}_{0.45} \mathrm{Ta}_{0.08} \mathrm{~N}$ and $\mathrm{Ti}_{0.43} \mathrm{Al}_{0.42} \mathrm{Ta}_{0.15} \mathrm{~N}$ still exhibit a small mass-reduction after the distinct mass-loss between $1300-1400^{\circ} \mathrm{C}$.

The decreasing area under the DSC curves is indicative for a decreased stored energy within the coatings with increasing Ta content. This is predicted by Holec et al. [11] as alloying $\mathrm{Ti}_{1-x} \mathrm{Al}_{x} \mathrm{~N}$ with tantalum should result in reduced mixing enthalpies and thereby in a reduced driving force for decomposition of the supersaturated phases into isostructural components. Consequently, the onset and intensity of the decomposition is shifted to higher temperatures and thereby also the subsequent phase transformation of Al rich cubic domains (or even fcc-AIN) to the stable modification hcp-AIN, see Fig. 3a. A corresponding behavior is obtained for our Al rich coatings. In sound agreement to previous studies on $\mathrm{Ti}_{1-x} \mathrm{Al}_{x} \mathrm{~N}$ coatings (sputtered or arc-evaporated) $[27,28,31,32]$ the peak temperature of the pronounced exothermic feature (due to the phase transformation of fcc-AIN to hcp-AIN) shifts to lower temperatures with increasing $\mathrm{Al}$ content, compare Figs. $3 a$ and $b$. This is based on the increased driving force for decomposition of the supersaturated $\mathrm{Ti}_{1-x} \mathrm{Al}_{x} \mathrm{~N}$ matrix into their components fcc-TiN and 
fcc-AIN with increasing Al content. As the peak-temperature of the fcc-hcp phase transformation of $\mathrm{Ti}_{0.35} \mathrm{Al}_{0.65} \mathrm{~N}$ with $1050{ }^{\circ} \mathrm{C}$ is at lower temperatures, as for the lower $\mathrm{Al}$ containing $\mathrm{Ti}_{0.51} \mathrm{Al}_{0.49} \mathrm{~N}$, also the mass-loss starts earlier, see Fig. 3b. Nevertheless, almost at the same temperature of $1300{ }^{\circ} \mathrm{C}$ the mass-loss is completed. Again the addition of Ta to $\mathrm{Ti}_{1-\mathrm{x}} \mathrm{Al}_{\mathrm{x}} \mathrm{N}$ shifts the peak temperature for the fcc-hcp phase transformation to higher temperatures and hence also the mass-loss. However, the TGA curve suggests that with increasing Ta content the mass-loss still proceeds (with a significantly reduced rate) after the distinct mass-loss of $\sim 1.3$ and $2 \%$ for the high and medium Al containing coatings, respectively. The decreasing mass-loss between high and medium Al containing coatings corresponds with a decreasing $\mathrm{Ti}$ content. This suggests that the nitrogen loss strongly correlates with the Ti content. According to the Ti-N phase diagram [33] fcc-TiN exhibits a broad chemical stability range and allows for a nitrogen release while still keeping the fcc structure. On the other hand AIN is known to be a line compound with only a very limited chemical stability range [34].

Powder XRD patterns after DSC-TGA measurements to $1600{ }^{\circ} \mathrm{C}$ clearly show that the Ta free coatings $\mathrm{Ti}_{0.51} \mathrm{Al}_{0.49} \mathrm{~N}$, Fig. $4 \mathrm{a}$, and $\mathrm{Ti}_{0.35} \mathrm{Al}_{0.65} \mathrm{~N}$, Fig. 4b, are completely decomposed into their stable constituents fcc-TiN and hcp-AIN. With increasing Ta content the positions of the fcc XRD peaks shift to lower diffraction angles from fcc-TiN to fcc-TaN, indicative for the solid solution between TiN and TaN. For the high Ta containing coatings $\mathrm{Ti}_{0.43} \mathrm{Al}_{0.42} \mathrm{Ta}_{0.15} \mathrm{~N}$ and $\mathrm{Ti}_{0.30} \mathrm{Al}_{0.54} \mathrm{Ta}_{0.16} \mathrm{~N}$ the formation of hexagonal (hex) $\mathrm{Ta}_{2} \mathrm{~N}$ [35] can be detected by XRD. This is especially pronounced for the high Al containing 
$\mathrm{Ti}_{0.30} \mathrm{Al}_{0.54} \mathrm{Ta}_{0.16} \mathrm{~N}$, compare Figs. $4 \mathrm{a}$ and $\mathrm{b}$, and in agreement to TGA measurements, Fig. 3, which exhibit an increasing mass-loss with increasing Ta content.

\subsection{Oxidation Resistance}

At the initial stage of oxidation the mass-gain $w$ usually follows a linear rate law with time $t$ :

$$
w=k_{l} t
$$

where $k_{l}$ the linear rate constant. The rate limiting reaction step of this stage is the surface reaction of oxygen or the diffusion through the gas phase and is often denoted as "Regime 1" [36]. As soon as a dense oxide scale is formed on top of the nitride coating the mass-gain rate is retarded and controlled by the diffusion of the reactants through the scale. This bulk/grain-boundary diffusion is based on Fick's diffusion law and here the mass-gain usually follows a parabolic rate law (“Regime 2"):

$$
w=\sqrt{k_{p} t}
$$

where $k_{p}$ is the parabolic rate constant $[37,38]$. In the case of high temperature oxidation, often a paralinear behavior is observed, where a predominant parabolic Regime 2 is accompanied by a linear rate-law:

$$
w=\sqrt{k_{p} t}+c k_{l} t
$$


with a reduced (by the prefactor c; usually much smaller than 1 ) linear rate constant. This is the case if the formed oxide scale suffers damage e.g. due to cracks [39]. As soon as the parabolic Regime 2 is reached, the mass-gain and hence film degradation can effectively be retarded and hence $k_{p}$ is a characteristic parameter for describing the quality of the formed scale. $k_{p}$ is usually given as

$$
k_{p}=\left(\frac{\Delta m}{A}\right)^{2} \cdot \frac{1}{t}
$$

, where the mass gain $\Delta m$ is related to the exposed surface area $A$ and time $t$. Within this study we have used flake-like coating material, which can be described by plates having a top and a bottom surface area $A$ and a thickness $d$ (equal to the coating thickness $d$ ). If these plates are large (their volume to surface ratio high) their lateral surface area (coating thickness times plate perimeter) can be neglected and the rate constant for flake-like coating powder $k_{p}^{*}$ can be related to $\mathrm{k}_{\mathrm{p}}$ by

$$
k_{p}^{*} \cdot\left(\frac{\rho d}{2}\right)^{2}=k_{p}
$$

, where $\rho$ is the density of the coating. Consequently the rate constant is defined as

$$
k_{p}^{*}=\left(\frac{\Delta m}{m_{0}}\right)^{2} \cdot \frac{1}{t}
$$

, where $m_{0}$ is the weighed portion of the flake-like nitride coating material. The factor $\left(\frac{\rho d}{2}\right)^{2}$ is different for the different coatings, but does not influence activation 
energy evaluations by Arrhenius plots as it is constant for the different treatment temperatures.

Figure $5 \mathrm{a}$ shows the isothermal DSC and TGA curves of $\mathrm{Ti}_{0.51} \mathrm{Al}_{0.49} \mathrm{~N}, \mathrm{Ti}_{0.47} \mathrm{Al}_{0.45} \mathrm{Ta}_{0.08} \mathrm{~N}$, and $\mathrm{Ti}_{0.43} \mathrm{Al}_{0.42} \mathrm{Ta}_{0.15} \mathrm{~N}$ in synthetic air at $850{ }^{\circ} \mathrm{C}$. The DSC signal clearly shows that the exothermic signal initially rapidly increases and soon decreases again. The increase in heat-flow corresponds to the formation of an oxide scale on top of the nitride layer. A decreasing heat flow after the peak value suggests either a completed nitride-to-oxide transformation or that the oxidation process is effectively retarded by the formation of a dense protective oxide. The latter is the case for our coatings as the TGA signal shows a pronounced reduction in mass-gain-rate without reaching the maximum mass-gain due to a completed nitride-to-oxide transformation. After a linear Regime 1, also in our case the Ta free $\mathrm{Ti}_{0.51} \mathrm{Al}_{0.49} \mathrm{~N}$ coating follows a parabolic growth rate at $850{ }^{\circ} \mathrm{C}$ with $k_{p}^{*}=1.83 \mathrm{x}$ $10^{-3} 1 / \mathrm{s}$ (parabolic fits are indicated by the dashed lines). Again increasing mass-gain rates after 60 min of oxidation suggest for a failure (e.g. cracks) of the formed oxide scale. The small inset in Fig. 5a shows a magnification of the first 9 minutes of the DSC signal, indicating that the onset of the exothermic signal due to oxidation is similar for all three coatings. Nevertheless, the intensity as well as the time of the oxidation peak decreases with increasing Ta content. Even more important is that the exothermic output after this peak-reaction also decreases with increasing Ta content. This clearly suggests that with increasing Ta content the oxide scale formed is denser and hence more effective in reducing the oxidation process. This is proven by the TGA measurements showing that 
$\mathrm{Ti}_{0.51} \mathrm{Al}_{0.49} \mathrm{~N}$ is already fully oxidized after $\sim 120 \mathrm{~min}$ as the mass-gain levels out at $22 \%$. This value is close to the theoretical possible mass-gain of $\sim 27 \%$ if the nitride fully transforms into $\mathrm{TiO}_{2}$ and $\mathrm{Al}_{2} \mathrm{O}_{3}$. Deviations from the theoretical mass-gain can be explained by the commonly observed over-stoichiometry of $\operatorname{Ti}_{1-x} \mathrm{Al}_{x} \mathrm{~N}$ and the substoichiometry of $\mathrm{TiO}_{2}[1,19,40]$. As a consequence, this leads to a higher mass-loss due to the nitrogen release (from overstoichiometric nitrides as compared to stoichiometric nitrides) and a lower mass-gain due to oxidation (to substoichiometric $\mathrm{TiO}_{2}$ as compared to stoichiometric $\mathrm{TiO}_{2}$ ). At that point we also want to notice that an EDX chemical analysis is especially for light elements (like $\mathrm{N}$ ) not very precise and therefore this might have also an influence on the measured mass-gain during oxidation.

The mass-gain-rate is effectively reduced with increasing Ta content and follows a parabolic-like growth with constants of $k_{p}^{*}=7.2 \times 10^{-4}$ and $5.8 \times 10^{-4} 1 / \mathrm{s}$ for $\mathrm{Ti}_{0.47} \mathrm{Al}_{0.45} \mathrm{Ta}_{0.08} \mathrm{~N}$ and $\mathrm{Ti}_{0.43} \mathrm{Al}_{0.42} \mathrm{Ta}_{0.15} \mathrm{~N}$, respectively. Even after $5 \mathrm{~h}$ exposure to synthetic air at $850^{\circ} \mathrm{C}$ the coatings are far from being fully oxidized.

The Al rich coatings show an even improved oxidation resistance, Fig. 5b. The initial oxidation process within the first minutes of exposure to synthetic air is significantly reduced and the heat flow decreases earlier. Compare the insets in Figs. $5 \mathrm{a}$ and b. This suggests that the oxide scale formed is even denser as for their lower Al containing counterparts, which is also confirmed by the mass-gain-curves. Within the first two hours the mass-gain-curve of $\mathrm{Ti}_{0.35} \mathrm{Al}_{0.65} \mathrm{~N}$ can also be described by a first linear Regime 1 which 
is followed by a parabolic behavior with $k_{p}^{*}=3.15 \times 10^{-4} 1 / \mathrm{s}$, to be followed by a linearlike oxidation behavior. The latter is indicative for the formation of many cracks within the scale or even spallation of parts of the oxide scale and hence increased diffusion and exposure of unprotected - by the oxide scale - nitride material. Nevertheless, the massgain of $\sim 12 \%$ after $5 \mathrm{~h}$ indicates that only $\sim 1 / 2$ of the nitride coating is transferred into $\mathrm{TiO}_{2}$ and $\mathrm{Al}_{2} \mathrm{O}_{3}$. For a completed oxidation of $\mathrm{Ti}_{0.35} \mathrm{Al}_{0.65} \mathrm{~N}$ the theoretical mass-gain would be $\sim 26.5 \%$. Corresponding to the medium Al containing coatings, the oxidation resistance can effectively be increased with increasing Ta content. The parabolic growth rate Regime 2 of the mass-gain-curves of $\mathrm{Ti}_{0.32} \mathrm{Al}_{0.60} \mathrm{Ta}_{0.08} \mathrm{~N}$ and $\mathrm{Ti}_{0.30} \mathrm{Al}_{0.54} \mathrm{Ta}_{0.16} \mathrm{~N}$ can be described with $k_{p}^{*}=1.23 \times 10^{-4}$ and $k_{p}^{*}=1.60 \times 10^{-4} 1 / \mathrm{s}$. Increasing the oxidation temperature to $950{ }^{\circ} \mathrm{C}$ is extremely demanding for Ta free $\mathrm{Ti}_{0.51} \mathrm{Al}_{0.49} \mathrm{~N}$ and $\mathrm{Ti}_{0.35} \mathrm{Al}_{0.65} \mathrm{~N}$. For both coatings, DSC can detect a pronounced exothermic output within the first 15 min of exposure, and the mass-gain also suggests that the coatings are soon completely oxidized, see Figs. $6 a$ and $b$. Their mass-gain follows a linear-like behavior. The higher Al containing coating slows down the initially pronounced oxidation process within the first five minutes, as suggested by the decreasing heat flow and the slightly reduced massgain rate. Therefore, we were also able to determine the parabolic rate-constant for this short term with $k_{p}^{*}=2.40 \times 10^{-3} 1 / \mathrm{s}$. But already after $\sim 2 \mathrm{~min}$, again enhanced oxidation reactions occur leading to a pronounced linear-like increase in mass. This behavior suggests a pronounced breakaway oxidation process.-The lower Al containing coating, $\mathrm{Ti}_{0.51} \mathrm{Al}_{0.49} \mathrm{~N}$, exhibits no formation of a dense oxide, which is indicated by only linear 
growth in the mass gain curve from the beginning to the end. The heat-flow only decreases at the end of the oxidation process ( $12 \mathrm{~min}$ ) when the coating is completely oxidized, suggesting that here not even the initial stage of a protecting oxide scale (Regime 2) can be formed.

However, for both coating types (medium and high Al content) the addition of Ta significantly improves their oxidation resistance, as the exothermic output as well as the mass-gain is significantly reduced. For the medium Al containing films the heat flow decreases after $\sim 3$ and 2 min for $\mathrm{Ti}_{0.47} \mathrm{Al}_{0.45} \mathrm{Ta}_{0.08} \mathrm{~N}$ and $\mathrm{Ti}_{0.43} \mathrm{Al}_{0.42} \mathrm{Ta}_{0.15} \mathrm{~N}$, respectively, indicating the formation of a protective oxide scale. The mass-gain of $\mathrm{Ti}_{0.43} \mathrm{Al}_{0.42} \mathrm{Ta}_{0.15} \mathrm{~N}$ follows a parabolic growth rate with $k_{p}^{*}=4.50 \times 10^{-4} 1 / \mathrm{s}$ until the maximum testing time of $5 \mathrm{~h}$, whereas for the lower Ta containing $\mathrm{Ti}_{0.47} \mathrm{Al}_{0.45} \mathrm{Ta}_{0.08} \mathrm{~N}$ only the first hour can be described by a parabolic growth rate with $k_{p}^{*}=1.13 \times 10^{-3} 1 / \mathrm{s}$. The latter exhibits after $\sim 1$ $\mathrm{h}$ an increased mass-gain, corresponding to paralinear oxidation (see equation 3 ) due to significant cracking of the protective oxide scale, which results after $5 \mathrm{~h}$ to a completed oxidation. Contrary, the higher Ta containing coating does not show such an additional linear oxidation behavior and the mass-gain suggests that only $\sim 57 \%$ of the nitride is transferred to $\mathrm{TiO}_{2}, \mathrm{Al}_{2} \mathrm{O}_{3}$, and $\mathrm{Ta}_{2} \mathrm{O}_{5}$ after $5 \mathrm{~h}$, Fig. $6 \mathrm{a}$. With increasing $\mathrm{Al}$ content the $\mathrm{Ta}$ addition is even more effective, but of utmost importance is, that here the lower Ta containing $\mathrm{Ti}_{0.32} \mathrm{Al}_{0.60} \mathrm{Ta}_{0.08} \mathrm{~N}$ follows the parabolic mass-gain with a smaller rate constant $k_{p}^{*}=1.40 \times 10^{-4} 1 / \mathrm{s}$ than that of the higher Ta containing counterpart $\operatorname{Ti}_{0.30} \mathrm{Al}_{0.54} \operatorname{Ta}_{0.16} \mathrm{~N}\left(k_{p}^{*}\right.$ 
$=2.40 \times 10^{-4} 1 / \mathrm{s}$ ), Fig. 6b. The mass-gain (measured by an external balance; see Table 1 ) of 6.4 and $10.2 \%$ after $5 \mathrm{~h}$ exposure to air at $950{ }^{\circ} \mathrm{C}$ suggests that 28 and $49 \%$ of $\mathrm{Ti}_{0.32} \mathrm{Al}_{0.60} \mathrm{Ta}_{0.08} \mathrm{~N}$ and $\mathrm{Ti}_{0.30} \mathrm{Al}_{0.54} \mathrm{Ta}_{0.16} \mathrm{~N}$ are oxidized, respectively.

XRD investigations of the Ta free coatings $T_{0.51} \mathrm{Al}_{0.49} \mathrm{~N}$ and $\mathrm{Ti}_{0.35} \mathrm{Al}_{0.65} \mathrm{~N}$ after isothermal DSC-TGA in air for $5 \mathrm{~h}$ at $850{ }^{\circ} \mathrm{C}$ reveal a rutile $\left(r-\mathrm{TiO}_{2}\right)$ [41], anatase $\left(\mathrm{a}-\mathrm{TiO}_{2}\right)$ [42], and corundum $\left(\alpha-\mathrm{Al}_{2} \mathrm{O}_{3}\right)$ [43] type oxide scale structure, Figs. 7a and b. For the higher Al containing $\mathrm{Ti}_{0.35} \mathrm{Al}_{0.65} \mathrm{~N}$ coating, additional broad XRD peaks at diffraction angles of $\sim 37^{\circ}$ and $\sim 43^{\circ}$ suggest the presence of $f c c-\mathrm{Ti}_{1-x} \mathrm{Al}{ }_{x} \mathrm{~N}$. Furthermore, also indications for monoclinic Al oxides ( $\left.\mathrm{m}-\mathrm{AlO}_{\mathrm{x}}[44]\right)$ and hcp-AIN can be detected. This is in agreement to TGA suggesting no completed oxidation of the nitride layer during the $5 \mathrm{~h}$ oxidation treatment. Here, the fcc-AIN to hcp-AIN transformation could be additionally responsible for the again increasing mass-gain-rate at an exposure time of $180 \mathrm{~min}$. With the addition of Ta to both, medium and high $\mathrm{Al}$ containing $\mathrm{Ti}_{1-\mathrm{x}} \mathrm{Al} \mathrm{X}_{x} \mathrm{~N}$, coatings the formation of the anatase phase is suppressed and the oxide scale predominantly exhibits rutile. This does not necessarily imply that Al has to be dissolved in a rutile phase, as especially an Al oxide - if very thin - is difficult to detect and can be amorphous like $[8,24]$.

While the intensity of the rutile phase decreases with increasing Ta content, the overall contribution of the $\mathrm{Ti}_{1-x-y} \mathrm{Al}_{x} \mathrm{Ta}_{y} \mathrm{~N}$ phase increases. Furthermore, no hcp-AIN can be detected for these Ta containing nitrides. These results are in excellent agreement to DSC-TGA in inert (He) and oxidizing atmosphere (synthetic air) showing that with the 
addition of Ta the hcp-AIN formation is shifted to higher temperatures and only a small fraction of the nitride coating is oxidized. Increasing the oxidation temperature to $950{ }^{\circ} \mathrm{C}$ leads also - in addition to the full oxidation of $\mathrm{Ti}_{0.51} \mathrm{Al}_{0.49} \mathrm{~N}$ Fig. $8 \mathrm{a}$ - to a complete oxidation of the Al rich $\mathrm{Ti}_{0.35} \mathrm{Al}_{0.65} \mathrm{~N}$, see Fig. $8 \mathrm{~b}$. There are no detectable remaining nitride phases present for these coatings after the oxidation at $950{ }^{\circ} \mathrm{C}$ for $5 \mathrm{~h}$. The oxides are composed of rutile and corundum type phases, no anatase can be detected by XRD. For this high temperature, also the Ta containing $\mathrm{Ti}_{0.47} \mathrm{Al}_{0.45} \mathrm{Ta}_{0.08} \mathrm{~N}$ (lowest $\mathrm{Ta}$ and medium $\mathrm{Al}$ content) is completely oxidized, Fig. 8a, as already suggested by the corresponding DSCTGA curves, see Fig. 6a. A further increase in Ta content to form $\operatorname{Ti}_{0.43} \mathrm{Al}_{0.42} \mathrm{Ta}_{0.15} \mathrm{~N}$ allows for the formation of a protective dense oxide scale and hence, the presence of fcc- $\mathrm{Ti}_{1-\mathrm{x}-}$ ${ }_{y} \mathrm{Al}_{x} \mathrm{Ta}_{\mathrm{y}} \mathrm{N}$ can still be detected (broad XRD peaks at $2 \theta$ angles of $\sim 37^{\circ}$ and $43^{\circ}$ ). For higher Al containing coatings this is valid even for the lower Ta content, see Fig. 8b. Similar to the structure after oxidation at $850{ }^{\circ} \mathrm{C}$ the oxides are predominantly composed of rutile phase (no anatase), but due to the higher temperature of $950{ }^{\circ} \mathrm{C}$, here also low intensity $\alpha-\mathrm{Al}_{2} \mathrm{O}_{3}$ can be detected.

With the help of Arrhenius plots, we calculate activation energies for the formation of a dense oxide scale using the parabolic rate constants $k_{p}^{*}$ (Regime 2 ). This yields $\sim 232$ $\mathrm{kJ} / \mathrm{mol}$ for the high Al containing coating $\mathrm{Ti}_{0.35} \mathrm{Al}_{0.65} \mathrm{~N}$. Tantalum additions lead to significantly reduced activation energies of $14.8 \mathrm{~kJ} / \mathrm{mol}$ for $\mathrm{Ti}_{0.32} \mathrm{Al}_{0.60} \mathrm{Ta}_{0.08} \mathrm{~N}$ and 46.3 $\mathrm{kJ} / \mathrm{mol}$ for $\mathrm{Ti}_{0.30} \mathrm{Al}_{0.54} \mathrm{Ta}_{0.16} \mathrm{~N}$. Consequently, the energy barrier for the stable Regime 2 
behavior is reduced by a factor of $\sim 5$ for $\mathrm{Ti}_{0.30} \mathrm{Al}_{0.54} \mathrm{Ta}_{0.16} \mathrm{~N}$ and $\sim 15$ for $\mathrm{Ti}_{0.32} \mathrm{Al}_{0.60} \mathrm{Ta}_{0.08} \mathrm{~N}$ as compared to conventional $\operatorname{Ti}_{0.35} \mathrm{Al}_{0.65} \mathrm{~N}$, indicating that the passivation process is fastest and easiest for $\mathrm{Ti}_{0.32} \mathrm{Al}_{0.60} \mathrm{Ta}_{0.08} \mathrm{~N}$. For medium Al containing $\mathrm{Ti}_{0.47} \mathrm{Al}_{0.45} \mathrm{Ta}_{0.08} \mathrm{~N}$, the activation energy with $51.5 \mathrm{~kJ} / \mathrm{mol}$ is comparable to $\mathrm{Ti}_{0.30} \mathrm{Al}_{0.54} T_{0.16} \mathrm{~N}$. Please note that we have used $k_{p}^{*}$ of only two different temperatures $\left(850\right.$ and $\left.950{ }^{\circ} \mathrm{C}\right)$ and hence these activation energies can just be used for rating the different coatings within this study.

Table 1 summarizes the above presented data for our coatings, obtained by XRD and isothermal DSC-TGA at 850 and $950{ }^{\circ} \mathrm{C}$. This allows for a clear and detailed comparison of the individual effect of $\mathrm{Al}$ and Ta on the oxidation behavior of our $\operatorname{Ti}_{1-x-y} \mathrm{Al}_{\mathrm{x}} \operatorname{Ta}_{y} \mathrm{~N}$ coatings.

Generally, the two following major conclusions can be drawn from the oxidation experiments. As long as the nitride coating exhibits a single phase structure and no nitride phase transformations occur at the oxidation temperature, increasing Al contents significantly reduce the oxidation processes. The addition of Ta to form single-phase fcc$\mathrm{Ti}_{1-\mathrm{x}-\mathrm{A}} \mathrm{Al}_{\mathrm{x}} \mathrm{Ta}_{\mathrm{y}} \mathrm{N}$ further reduces the oxidation process by promoting the formation of a protective dense oxide scale. However, the detailed investigations clearly show that the Ta content needs to be balanced with the Al content. Moreover, the ideal chemical composition for optimized oxidation resistance also depends on the application temperature.

Cross sectional SEM investigations of the coatings after exposure to ambient air for $20 \mathrm{~h}$ at 850 and $950{ }^{\circ} \mathrm{C}$ clearly show that the Ta free coatings $\mathrm{Ti}_{0.51} \mathrm{Al}_{0.49} \mathrm{~N}$ and $\mathrm{Ti}_{0.35} \mathrm{Al}_{0.65} \mathrm{~N}$ are 
fully oxidized and exhibit a porous morphology, like shown in Fig. 9a for $\operatorname{Ti}_{0.35} \mathrm{Al}_{0.65} \mathrm{~N}$. As suggested by DSC-TGA the Ta alloyed coatings are able to form a dense oxide scale during exposure to air at $850{ }^{\circ} \mathrm{C}$, allowing for a reduced oxidation rate and a parabolic-like growth behavior. Such a dense oxide scale formation, after $20 \mathrm{~h}$ at $850{ }^{\circ} \mathrm{C}$, is shown for $\mathrm{Ti}_{0.43} \mathrm{Al}_{0.42} \mathrm{Ta}_{0.15} \mathrm{~N}$ in Fig. 9b. However, by increasing the temperature to $950{ }^{\circ} \mathrm{C}$ the oxides formed on $\mathrm{Ti}_{0.47} \mathrm{Al}_{0.45} \mathrm{Ta}_{0.08} \mathrm{~N}, \mathrm{Ti}_{0.43} \mathrm{Al}_{0.42} \mathrm{Ta}_{0.15} \mathrm{~N}$, as well as $\mathrm{Ti}_{0.30} \mathrm{Al}_{0.54} \mathrm{Ta}_{0.16} \mathrm{~N}$ are composed of a porous region at the coating-scale interface and a denser outermost region. This is shown in Fig. 9c for $\mathrm{Ti}_{0.30} \mathrm{Al}_{0.54} \mathrm{Ta}_{0.16} \mathrm{~N}$, which performed best during DSC-TGA at $950{ }^{\circ} \mathrm{C}$ among these three Ta containing coatings. The coating with the smallest parabolic growth rate constant $\left(k_{p}^{*}\right.$ of $1.40 \times 10^{-4} 1 / \mathrm{s}$ ) during isothermal oxidation at $950{ }^{\circ} \mathrm{C}$ is $\mathrm{Ti}_{0.32} \mathrm{Al}_{0.60} \mathrm{Ta}_{0.08} \mathrm{~N}$ (see table 1 ), which exhibits only a very thin ( $100 \mathrm{~nm}$ ) porous region at the interface between nitride and the dense outermost oxide scale, see Fig. 9d. Please notice that the magnification for Fig. 9d is increased as compared to Figs. 9a-c to clearly present the only $\sim 1 \mu \mathrm{m}$ thin oxide scale.

The presented results on the oxidation behavior of as-deposited single-phase cubic $\mathrm{Ti}_{1-\mathrm{x}-}$ ${ }_{y} \mathrm{Al}_{x} \mathrm{Ta}_{y} \mathrm{~N}$ with the main data summarized in Table 1 raise the question on the role of the anatase phase, its dependence on the Ta content, and the role of the chemical composition, which will be discussed in the next section. 


\section{Discussion}

Oxidizing the Ta free $\mathrm{Ti}_{0.51} \mathrm{Al}_{0.49} \mathrm{~N}$ and $\mathrm{Ti}_{0.35} \mathrm{Al}_{0.65} \mathrm{~N}$ at $850{ }^{\circ} \mathrm{C}$ causes the formation of rutile, anatase, and corundum phase fractions. By increasing the temperature to $950{ }^{\circ} \mathrm{C}$ no anatase can be detected anymore, and the oxides consist of only rutile and corundum phases. For a better understanding of the mechanisms behind, we have stopped the isothermal DSC-TGA treatments after specific times of oxidation. These samples are analyzed in detail by XRD. If $\mathrm{Ti}_{0.51} \mathrm{Al}_{0.49} \mathrm{~N}$ is oxidized for $2.5 \mathrm{~min}$ at $850^{\circ} \mathrm{C}$ (directly after the first exothermic peak, see Fig. 5a) mainly anatase, only small amounts of rutile, and almost no corundum phases can be detected, Fig. 10a. After this short exposure to air the nitride phase fcc- $\mathrm{Ti}_{1-\mathrm{x}} \mathrm{Al} \mathrm{I}_{\mathrm{X}} \mathrm{N}$ is still clearly present, please compare the corresponding XRD pattern with the as-deposited pattern at the bottom. Increasing the exposure time to 120 min (where the mass-gain reached its saturation, Fig. 5a) results in a completed oxidation of the nitride into anatase, rutile, and corundum phases. Upon further increasing the exposure time to $300 \mathrm{~min}(5 \mathrm{~h})$ the rutile phase fraction increases at the expense of anatase. Generally, the anatase-to-rutile phase transformation would occur in the temperature range $550-700{ }^{\circ} \mathrm{C}[45,46]$ but the presence of other alloying elements like Al or $\mathrm{N}$ can further influence this transformation temperature $[47,48]$. However, also for the higher Al containing coating $\mathrm{Ti}_{0.35} \mathrm{Al}_{0.65} \mathrm{~N}$ the formation of anatase can be detected at an even higher oxidation temperature of $950^{\circ} \mathrm{C}$ during the initial stage of oxidation. The XRD pattern taken after 4 min of exposure at $950{ }^{\circ} \mathrm{C}$, Fig. $10 \mathrm{~b}$, clearly shows the presence of anatase, small fractions of rutile, and corundum phases in addition to the nitride 
phases hcp-AIN, fcc-Ti ${ }_{1-x} \mathrm{Al}_{x} \mathrm{~N}$, and fcc structured $\mathrm{Ti}$ and $\mathrm{Al}$ rich domains. The latter originate from spinodal decomposition of the supersaturated $\mathrm{Ti}_{1-x} \mathrm{Al}_{x} \mathrm{~N}$ matrix $[6,29,31,49]$. Upon further exposure no nitrides can be detected anymore and the oxide phase anatase completely transforms into rutile. Based on these detailed XRD investigations we can conclude that the initial Ti oxide formed on medium and high $\mathrm{Al}$ containing single-phase fcc- $-\mathrm{Ti}_{1-x} \mathrm{Al}_{x} \mathrm{~N}$ is anatase, at least in this industrially important temperature range up to $950{ }^{\circ} \mathrm{C}$. Due to the high temperature, anatase continuously transforms into rutile with progressing oxidation time. As this transformation is accompanied by a volume shrinkage of 5-10 \% (rutile has a lower specific volume than anatase) $[50,51]$, the formation of cracks and/or pores (Fig. 9a) is promoted leading to paralinear or even linear mass-gain-rates, Figs. 5 and 6 . The formation of pores, especially at interfaces, also originates from different diffusion rates of the involved species, which is known as Kirkendall effect [52,53]. Especially at temperatures above $800{ }^{\circ} \mathrm{C}$ also the rapid outward diffusion of Al easily leads to the formation of voids $[1,9,54]$.

The oxidation behavior of Ta alloyed $\mathrm{Ti}_{1-x} \mathrm{Al}_{x} \mathrm{~N}$ coatings is especially different with respect to the anatase formation, which in contrast to $\mathrm{Ti}_{1-x} \mathrm{Al}_{x} \mathrm{~N}$ cannot be observed by XRD during oxidation at 850 or $950{ }^{\circ} \mathrm{C}$. Small fractions of crystalline corundum oxide can only be detected for the treatment at $950{ }^{\circ} \mathrm{C}$, see Figs. $8 \mathrm{a}$ and b. This is in agreement to the oxide scale morphology of Ta alloyed coatings being uniform in contrast to $\mathrm{Ti}_{1-x} \mathrm{Al} \mathrm{l}_{x} \mathrm{~N}$, Fig. 9. As rutile $\mathrm{TaO}_{2}$ is one of the most stable substoichiometric phases of $\mathrm{Ta}_{2} \mathrm{O}_{5}[55,56]$, we suggest that Ta stabilizes the formation of rutile phases already during the initial stages 
of oxidation of Ta alloyed $\operatorname{Ti}_{1-x} \mathrm{Al}_{x} \mathrm{~N}$. Based on the XRD experiments, exhibiting almost a perfect match of the rutile oxide peaks to the diffraction file of $\mathrm{r}-\mathrm{TiO}_{2}$, we envision that pentavalent Ta enables also the solubility of trivalent aluminum in rutile. This would also fit to the observation that the intensity of the $\alpha-\mathrm{Al}_{2} \mathrm{O}_{3}$ XRD peaks decreases with increasing Ta content, as the higher Ta content within the rutile phase allows also for a higher solubility of Al. The increasing broadening of the corresponding XRD peaks further supports this argument, as this indicates higher micro-strains and/or smaller grain sizes. Excess aluminum, which is not solved in the rutile phase, is responsible for the formation of $\alpha-\mathrm{Al}_{2} \mathrm{O}_{3}$, especially at high temperatures of $950{ }^{\circ} \mathrm{C}$, as $\alpha-\mathrm{Al}_{2} \mathrm{O}_{3}$ is the stable oxide [57].

In spite of this, a major advantage of alloying $\mathrm{Ta}$ to $\mathrm{Ti}_{1-x} \mathrm{Al}{ }_{x} \mathrm{~N}$ is the suppression of the anatase phase formation and the promotion of the high temperature rutile phase formation upon exposure to air. This is also supported by ab initio calculations and hence the destructive anatase-rutile phase transformation, which is typical during oxidation of $\mathrm{Ti}_{1-\mathrm{A}} \mathrm{Al}_{\mathrm{X}} \mathrm{N}$ (as shown here and in [58] for example), is avoided. As mentioned above, the anatase-rutile phase transformation is connected with a contraction of $5-10 \%[50,51]$ leading to crack formation and promotion of pores. We suggest, that the suppression of phase transformations within oxide scales is at least as important as reducing the bulk diffusion (as mentioned in earlier studies [24]), to reduce the oxide scale growth rate. This is especially valid for polycrystalline oxide scales on various materials, where the usually faster grain boundary diffusion is the rate-controlling factor. 


\section{Summary and Conclusion}

We have used DSC, TGA, SEM, and XRD to study in detail the thermal stability and oxidation resistance of arc-evaporated $\mathrm{Ti}_{1-x-y} \mathrm{Al}_{x} \operatorname{Ta}_{y} \mathrm{~N}$ hard coatings. By adding $\mathrm{Ta}$ up to $\mathrm{y}=$ 0.15 we could show that the stored mixing energy is significantly decreased and hence the thermal decomposition into the stable compounds is increased by $\sim 200{ }^{\circ} \mathrm{C}$. Considering the oxide scale formation of $\mathrm{Ti}_{1-x} \mathrm{Al}_{x} \mathrm{~N}$ during oxidation at $850^{\circ} \mathrm{C}$ and $950{ }^{\circ} \mathrm{C}$, the anatase-to-rutile phase transformation, which is accompanied by a volume change of $5-10 \%$, leads to the formation of pores, cracking, and maybe also to spallation of the scale. Consequently, only high Al containing $\operatorname{Ti}_{0.65} \mathrm{Al}_{0.35} \mathrm{~N}$ could resist complete oxidation after $5 \mathrm{~h}$ at $850{ }^{\circ} \mathrm{C}$, whereas at $950{ }^{\circ} \mathrm{C}$ medium and high $\mathrm{Al}$ containing coatings were oxidized within 15 min mainly due to a linear mass-gain behavior. Tantalum additions lead in all considered cases to an early formation of rutile phases with reduced or even completely suppressed anatase formation. Based on these results we conclude that pentavalent $\mathrm{Ta}$ enables the solubility of trivalent $\mathrm{Al}$ in a rutile structured $\mathrm{TiO}_{2}$ and the anatase-to-rutile phase transformations are avoided. Especially $\mathrm{Ti}_{0.32} \mathrm{Al}_{0.60} \mathrm{Ta}_{0.08} \mathrm{~N}$ exhibits an extremely dense oxide scale after oxidation at $950{ }^{\circ} \mathrm{C}$ in contrast to the other coatings. Consequently, here the Al and Ta content is well-balanced to guarantee for stable single phase nitride coating at the oxidation temperature and to allow for a direct and fast formation of rutile $(\mathrm{Ti}, \mathrm{Al}, \mathrm{Ta}) \mathrm{O}_{2}$ and corundum $\mathrm{Al}_{2} \mathrm{O}_{3}$. 
These results strongly indicate that the chemical composition of $X$ alloyed $\mathrm{Ti}_{1-x} \mathrm{Al}_{x} \mathrm{~N}$ coatings has to be optimized to the ternary $(\mathrm{Ti}, \mathrm{Al}, \mathrm{X})_{x} \mathrm{O}_{y}$ phase diagram to avoid anatase phase formation and hence gain significantly enhanced oxidation resistance. This could widely open up the field of applications of Ti-Al-N based hard coatings.

\section{Acknowledgements}

The financial support by the Austrian Federal Ministry of Economy, Family and Youth and the National Foundation for Research, Technology and Development is greatly acknowledged. The authors also want to thank Harald Leitner and Christopher Pöhl for their contribution to the DSC/TGA investigations. SEM investigations were carried out using facilities at the University Service Centre for Transmission Electron Microscopy (USTEM), Vienna University of Technology, Austria. Thanks are also due to the X-ray center (XRC) of Vienna University of Technology, Austria. 


\section{References}

[1] F. Vaz, L. Rebouta, M. Andritschky, M.F. da Silva, J.C. Soares, Thermal oxidation of Ti1 - xAlxN coatings in air, J. Eur. Ceram. Soc. 17 (1997) 1971-1977.

[2] F. Esaka, K. Furuya, H. Shimada, M. Imamura, N. Matsubayashi, T. Kikuchi, et al., Composition Dependence of the Initial Oxidation Films Studied by XAS and XPS, 1106 (1999) 1098-1106.

[3] H. Ichimura, A. Kawana, High-temperature oxidation of ion-plated TiN and TiAIN films, J. Mater. Res. 8 (1993) 1093-1100.

[4] J.-L. Huang, B.-Y. Shew, Effects of Aluminum Concentration on the Oxidation Behaviors of Reactively Sputtered TiAIN Films, J. Am. Ceram. Soc. 82 (2004) 696704.

[5] W.-D. Münz, Titanium aluminum nitride films: A new alternative to TiN coatings, J. Vac. Sci. Technol. A Vacuum, Surfaces, Film. 4 (1986) 2717.

[6] R. Rachbauer, S. Massl, E. Stergar, D. Holec, D. Kiener, J. Keckes, et al., Decomposition pathways in age hardening of Ti-Al-N films, J. Appl. Phys. 110 (2011) 023515.

[7] N. Christensen, I. Gorczyca, Calculated structural phase transitions of aluminum nitride under pressure., Phys. Rev. B. Condens. Matter. 47 (1993) 4307-4314.

[8] F. Rovere, P.H. Mayrhofer, A. Reinholdt, J. Mayer, J.M. Schneider, The effect of yttrium incorporation on the oxidation resistance of $\mathrm{Cr}-\mathrm{Al}-\mathrm{N}$ coatings, Surf. Coatings Technol. 202 (2008) 5870-5875.

[9] L. Chen, J. Paulitsch, Y. Du, P.H. Mayrhofer, Thermal stability and oxidation resistance of Ti-Al-N coatings., Surf. Coat. Technol. 206-318 (2012) 2954-2960.

[10] D. Holec, R. Rachbauer, L. Chen, L. Wang, D. Luef, P.H. Mayrhofer, Phase stability and alloy-related trends in Ti-Al-N, $\mathrm{Zr}-\mathrm{Al}-\mathrm{N}$ and $\mathrm{Hf}-\mathrm{Al}-\mathrm{N}$ systems from first principles, Surf. Coatings Technol. 206 (2011) 1698-1704.

[11] D. Holec, L. Zhou, R. Rachbauer, P.H. Mayrhofer, Alloying-related trends from first principles: An application to the Ti-Al-X-N system, J. Appl. Phys. 113 (2013) 113510. 
[12] R. Rachbauer, D. Holec, P.H. Mayrhofer, Phase stability and decomposition products of Ti-Al-Ta-N thin films, Appl. Phys. Lett. 97 (2010) 151901.

[13] R. Rachbauer, D. Holec, M. Lattemann, L. Hultman, P.H. Mayrhofer, Electronic origin of structure and mechanical properties in $\mathrm{Y}$ and $\mathrm{Nb}$ alloyed $\mathrm{Ti}-\mathrm{Al}-\mathrm{N}$ thin films, Int. J. Mater. Res. (formerly Zeitschrift Für Met. 102 (2011) 735-742.

[14] R. Rachbauer, A. Blutmager, D. Holec, P.H. Mayrhofer, Effect of Hf on structure and age hardening of Ti-Al-N thin films, Surf. Coatings Technol. (2011) 1-6.

[15] R. Rachbauer, D. Holec, P.H. Mayrhofer, Increased thermal stability of Ti-Al-N thin films by Ta alloying, Surf. Coatings Technol. 211 (2012) 98-103.

[16] L. Chen, D. Holec, Y. Du, P.H. Mayrhofer, Influence of Zr on structure, mechanical and thermal properties of Ti-Al-N., Thin Solid Films. 519 (2011) 5503-5510.

[17] M. Moser, P.H. Mayrhofer, Yttrium-induced structural changes in sputtered Ti1-xAlxN thin films, Scr. Mater. 57 (2007) 357-360.

[18] M. Moser, P.H. Mayrhofer, L. Székely, G. Sáfrán, P.B. Barna, Influence of bipolar pulsed DC magnetron sputtering on elemental composition and micro-structure of Ti-Al-Y-N thin films, Surf. Coatings Technol. 203 (2008) 148-155.

[19] H. Riedl, D. Holec, R. Rachbauer, P. Polcik, R. Hollerweger, J. Paulitsch, et al., Phase stability, mechanical properties and thermal stability of $\mathrm{Y}$ alloyed Ti-Al-N coatings, Surf. Coatings Technol. 235 (2013) 174-180.

[20] Y.X. Xu, L. Chen, B. Yang, Y.B. Peng, Y. Du, J.C. Feng, et al., Effect of $\mathrm{CrN}$ addition on the structure, mechanical and thermal properties of Ti-Al-N coating, Surf. Coatings Technol. 235 (2013) 506-512.

[21] A. Flink, J.M. Andersson, B. Alling, R. Daniel, J. Sjölén, L. Karlsson, et al., Structure and thermal stability of arc evaporated (Ti0.33Al0.67)1-xSixN thin films, Thin Solid Films. 517 (2008) 714-721.

[22] Y.-Y. Chang, S.-M. Yang, High temperature oxidation behavior of multicomponent TiAISiN coatings, Thin Solid Films. 518 (2010) S34-S37.

[23] R.G. Reddy, Y. Li, M.F. Arenas, Oxidation of a Ternary Ti3Al-Ta Alloy, High Temp. Mater. Process. 21 (2002) 195-206. 
[24] M. Pfeiler, C. Scheu, H. Hutter, J. Schnöller, C. Michotte, C. Mitterer, et al., On the effect of Ta on improved oxidation resistance of Ti-Al-Ta-N coatings, J. Vac. Sci. Technol. A Vacuum, Surfaces, Film. 27 (2009) 554.

[25] M. Pfeiler, G.A. Fontalvo, J. Wagner, K. Kutschej, M. Penoy, C. Michotte, et al., Arc Evaporation of Ti-Al-Ta-N Coatings: The Effect of Bias Voltage and Ta on Hightemperature Tribological Properties, Tribol. Lett. 30 (2008) 91-97.

[26] L. Vegard, Die Konstitution der Mischkristalle und die Raumfüllung der Atome, Zeitschrift Für Phys. 5 (1921) 17.

[27] P.H. Mayrhofer, D. Music, J.M. Schneider, Influence of the Al distribution on the structure, elastic properties, and phase stability of supersaturated Ti[sub 1-x]Al[sub x]N, J. Appl. Phys. 100 (2006) 094906.

[28] P.H. Mayrhofer, A. Hörling, L. Karlsson, J. Sjölén, T. Larsson, C. Mitterer, et al., Selforganized nanostructures in the Ti-Al-N system, Appl. Phys. Lett. 83 (2003) 2049.

[29] R. Rachbauer, J.J. Gengler, A.A. Voevodin, K. Resch, P.H. Mayrhofer, Temperature driven evolution of thermal, electrical, and optical properties of Ti-Al-N coatings, Acta Mater. 60 (2012) 2091-2096.

[30] Q. Xia, H. Xia, A.L. Ruoff, Pressure-induced rocksalt phase of aluminum nitride: A metastable structure at ambient condition, J. Appl. Phys. 73 (1993) 8198.

[31] P.H. Mayrhofer, L. Hultman, J.M. Schneider, P. Staron, H. Clemens, Spinodal decomposition of cubic Ti 1- $\mathrm{x} \mathrm{Al} \times \mathrm{N}$ : Comparison between experiments and modeling, Int. J. Mater. Res. 98 (2007) 1054-1059.

[32] L. Rogström, J. Ullbrand, J. Almer, L. Hultman, B. Jansson, M. Odén, Strain evolution during spinodal decomposition of TiAIN thin films, Thin Solid Films. 520 (2012) 5542-5549.

[33] J.-P. Bars, D. David, E. Etchessahar, J. Debuigne, Titanium $\alpha$ - nitrogen solid solution formed by high temperature nitriding: diffusion of nitrogen, hardness, and crystallographic parameters, Metall. Trans. A. 14 (1983) 1537-1543.

[34] Al - N ( Aluminium - Nitrogen ), in: Landolt-Börnstein - Gr. IV Phys. Chem. - Numer. Data Funct. Relationships Sci. Technol. Ag-Al to Au-TI, Springer, Berlin/Heidelberg, 2002: pp. 173-174.

[35] Powder Diffraction File 03-065-9404, International Center for Diffraction Data, PDF4/Release, 2010. 
[36] F. Rovere, Theoretical and experimental assessment of $\mathrm{Cr}-\mathrm{Al}-\mathrm{Y}-\mathrm{N}$ as protective coating for $\gamma$-TiAl based alloys, RWTH Aachen, 2010.

[37] P.H. Mayrhofer, H. Willmann, C. Mitterer, Oxidation kinetics of sputtered $\mathrm{Cr}-\mathrm{N}$ hard coatings, Surf. Coatings Technol. 146-147 (2001) 222-228.

[38] D. McIntyre, J.E. Greene, G. Håkansson, J.-E. Sundgren, W.-D. Münz, Oxidation of metastable single-phase polycrystalline Ti0.5Al0.5N films: Kinetics and mechanisms, J. Appl. Phys. 67 (1990) 1542.

[39] R.W. Revie, ed., Uhlig's Corrosion Handbook, 3. ed., John Wiley \& Sons, Hoboken, 2011.

[40] M.V. Ganduglia-Pirovano, A. Hofmann, J. Sauer, Oxygen vacancies in transition metal and rare earth oxides: Current state of understanding and remaining challenges, Surf. Sci. Rep. 62 (2007) 219-270.

[41] Powder Diffraction File 00-021-1276, International Center for Diffraction Data, PDF4/Release, 2010.

[42] Powder Diffraction File 00-021-1272, International Center for Diffraction Data, PDF4/Release, 2010.

[43] Powder Diffraction File 01-076-7774, International Center for Diffraction Data, PDF4/Release, 2010.

[44] Powder Diffraction File 01-079-1559, International Center for Diffraction Data, Pdf4/Release, 2010.

[45] S. Liao, Y. Chen, W.E. Mayo, B.H. Kear, TRANSFORMATION-ASSISTED CONSOLIDATION OF BULK NANOCRYSTALLINE TIO 2, 11 (1999) 553-557.

[46] B. Predel, O-Ti ( Oxygen-Titanium ), in: Landolt-Börnstein - Gr. IV Phys. Chem. Numer. Data Funct. Relationships Sci. Technol. Ni-Np - Pt-Zr, Springer, Berlin/Heidelberg, 1998.

[47] M. Iwase, K. Yamada, T. Kurisaki, H. Wakita, Characterization and photocatalytic activity of nitrogen-doped titanium(IV) oxide prepared by doping titania with TiN powder, Appl. Catal. A Gen. 455 (2013) 86-91.

[48] L.E. Depero, A. Marino, B. Allieri, E. Bontempi, L. Sangaletti, C. Casale, et al., Morphology and microstructural properties of TiO2 nanopowders doped with trivalent Al and Ga cations, J. Mater. Res. 15 (2011) 2080-2086. 
[49] P.H. Mayrhofer, F.D. Fischer, H.J. Böhm, C. Mitterer, J.M. Schneider, Energetic balance and kinetics for the decomposition of supersaturated Ti1-xAlxN, Acta Mater. 55 (2007) 1441-1446.

[50] D.A.H. Hanaor, C.C. Sorrell, Review of the anatase to rutile phase transformation, J. Mater. Sci. 46 (2010) 855-874.

[51] J. Muscat, V. Swamy, N. Harrison, First-principles calculations of the phase stability of TiO2, Phys. Rev. B. 65 (2002) 224112.

[52] W.M. Rainforth, Z. Zhou, On the structure and oxidation mechanisms in nanoscale hard coatings, J. Phys. Conf. Ser. 26 (2006) 89-94.

[53] S. Kekare, P. Aswath, Oxidation of TiAl based intermetallics, J. Mater. Sci. 2 (1997).

[54] A. Joshi, H. Hu, Oxidation behavior of titanium-aluminium nitrides, Surf. Coatings Technol. 77 (1995) 499-507.

[55] Y. Syono, M. Kikuchi, T. Goto, K. Fukuoka, Formation of rutile-type Ta(IV)O2 by shock reduction and cation-deficient $\mathrm{Ta} 0.8 \mathrm{O} 2$ by subsequent oxidation, J. Solid State Chem. 50 (1983) 133-137.

[56] J. Niebuhr, Die niederen oxide des tantals, J. Less Common Met. 10 (1966) 312-322.

[57] M. to Baben, Oxygen incorporation in MAX phases and TiAIN and elastic properties of nanolaminates, Shaker Verlag, 2013.

[58] C. Kim, K. Kim, Anti-oxidation properties of TiAIN film prepared by plasma-assisted chemical vapor deposition and roles of Al, Thin Solid Films. 307 (1997) 113-119.

[59] Powder Diffraction File 00-038-1420, International Center for Diffraction Data, PDF4/Release, 2010.

[60] Powder Diffraction File 00-046-1200, International Center for Diffraction Data, PDF4/Release, 2010. 


\section{Tables}

Table 1: Consumed coating material (calculated from the experimental mass-gain with respect to the theoretical mass-gain due to a complete transformation of $\mathrm{Ti}_{1-\mathrm{x}-\mathrm{y}} \mathrm{Al}_{\mathrm{x}} \mathrm{Ta}_{\mathrm{y}} \mathrm{N}$ into 1-x-y $\mathrm{TiO}_{2}, \mathrm{x} \mathrm{Al}_{2} \mathrm{O}_{3}$ and $\mathrm{y}$ $\mathrm{Ta}_{2} \mathrm{O}_{5}$ ), formed oxide phases ( $\mathrm{r}$ : rutile, a: anatase, $\alpha$ : corundum, m: monoclinic $\mathrm{AlO}_{\mathrm{x}}$ ) after $5 \mathrm{~h}$ of oxidation, oxidation rate constants $k_{p}^{*}$ for the parabolic regime (Regime 2), and activation energy $\mathrm{E}_{\mathrm{A}}$ for Regime 2 of $\mathrm{Ti}_{1-\mathrm{x}-\mathrm{y}} \mathrm{Al}_{\mathrm{x}} \mathrm{Ta}_{\mathrm{y}} \mathrm{N}$ coatings.

\begin{tabular}{|c|c|c|c|c|c|c|c|}
\hline \multirow[b]{2}{*}{ coating } & \multicolumn{2}{|c|}{$\begin{array}{l}\text { consumed coating } \\
\text { material }\end{array}$} & \multicolumn{2}{|c|}{ oxide phases } & \multicolumn{2}{|c|}{$\begin{array}{l}\text { rate constant, } k_{p}^{*} \\
\qquad\left(\left(\frac{\Delta \mathrm{m}}{\mathrm{m}_{0}}\right)^{2} * \frac{1}{t}\right)\end{array}$} & \multirow{2}{*}{$\begin{array}{c}\text { activation } \\
\text { energy, } E_{A} \\
{[\mathrm{~kJ} / \mathrm{mol}]}\end{array}$} \\
\hline & $\begin{array}{c}850{ }^{\circ} \mathrm{C} \\
{[\%]}\end{array}$ & $\begin{array}{c}950^{\circ} \mathrm{C} \\
{[\%]} \\
\end{array}$ & $850^{\circ} \mathrm{C}$ & $950^{\circ} \mathrm{C}$ & $\begin{array}{c}850^{\circ} \mathrm{C} \\
{[1 / \mathrm{s}]} \\
\end{array}$ & $\begin{array}{c}950^{\circ} \mathrm{C} \\
{[1 / \mathrm{s}]} \\
\end{array}$ & \\
\hline $\mathrm{Ti}_{0.51} \mathrm{Al}_{0.49} \mathrm{~N}$ & $83.3^{\mathrm{a}}$ & $83.5^{\mathrm{a}}$ & $r+a+\alpha$ & $r+\alpha$ & $1.83 * 10^{-3}$ & $-b$ & - \\
\hline $\mathrm{Ti}_{0.47} \mathrm{Al}_{0.45} \mathrm{Ta}_{0.08} \mathrm{~N}$ & 43.8 & $87.2^{a}$ & $r+\alpha$ & $r+\alpha$ & $7.20 * 10^{-4}$ & $1.13 * 10^{-3}$ & 51.5 \\
\hline $\mathrm{Ti}_{0.43} \mathrm{Al}_{0.42} \mathrm{Ta}_{0.15} \mathrm{~N}$ & 43.2 & 56.9 & $r$ & $r+\alpha$ & $5.80 * 10^{-4}$ & $4.50 * 10^{-4}$ & $-c$ \\
\hline $\mathrm{Ti}_{0.35} \mathrm{Al}_{0.65} \mathrm{~N}$ & 51.7 & $89.5^{\mathrm{a}}$ & $\mathrm{r}+\mathrm{a}+\alpha+\mathrm{m}$ & $r+\alpha$ & $3.15 * 10^{-4}$ & $2.40 * 10^{-3}$ & 232 \\
\hline $\mathrm{Ti}_{0.32} \mathrm{Al}_{0.60} \mathrm{Ta}_{0.08} \mathrm{~N}$ & 26.5 & 27.8 & r & $r+\alpha$ & $1.23 * 10^{-4}$ & $1.40 * 10^{-4}$ & 14.8 \\
\hline $\mathrm{Ti}_{0.30} \mathrm{Al}_{0.54} \mathrm{Ta}_{0.16} \mathrm{~N}$ & 20.9 & 48.9 & $r$ & $r+\alpha$ & $1.60 * 10^{-4}$ & $2.40 * 10^{-4}$ & 46.3 \\
\hline
\end{tabular}

${ }^{a}$ these coatings are actually fully oxidized, the difference in mass-gain to the theoretical mass-gain is related to possible nitrogen over-stoichiometry of the nitride phase and oxygen under-stoichiometry of the formed oxide phases.

${ }^{\mathrm{b}}$ just linear Regime 1 oxidation behavior detectable

${ }^{\mathrm{c}}$ here the Arrhenius plot shows actually a positive slope 


\section{Figure captions}

Fig.1: SEM fracture cross sections of $A$ rich coatings (a) $\operatorname{Ti}_{0.35} \mathrm{Al}_{0.65} \mathrm{~N}$, (b) $\operatorname{Ti}_{0.32} \mathrm{Al}_{0.60} \mathrm{Ta}_{0.08} \mathrm{~N}$, and (c) $\mathrm{Ti}_{0.30} \mathrm{Al}_{0.54} \mathrm{Ta}_{0.16} \mathrm{~N}$ in their as deposited state on high speed steel substrates.

Fig. 2: XRD patterns of (a) medium Al containing coatings $T_{0.51} \mathrm{Al}_{0.49} \mathrm{~N}, \mathrm{Ti}_{0.47} \mathrm{Al}_{0.45} \mathrm{Ta}_{0.08} \mathrm{~N}$, $\mathrm{Ti}_{0.45} \mathrm{Al}_{0.43} \mathrm{Ta}_{0.15} \mathrm{~N}$, and (b) high Al containing coatings $\mathrm{Ti}_{0.35} \mathrm{Al}_{0.65} \mathrm{~N}, \mathrm{Ti}_{0.32} \mathrm{Al}_{0.60} \mathrm{Ta}_{0.08} \mathrm{~N}$, and $\mathrm{Ti}_{0.30} \mathrm{Al}_{0.54} \mathrm{Ta}_{0.16} \mathrm{~N}$ in their as deposited state (after removing from their Fe-foil substrates). The peak positions for fcc-TiN, fcc-TaN, and fcc-AIN are taken from the ICDD database $[35,59,60]$.

Fig. 3: Dynamical DSC and TGA measurements of (a) medium Al containing coatings $\mathrm{Ti}_{0.51} \mathrm{Al}_{0.49} \mathrm{~N}, \mathrm{Ti}_{0.47} \mathrm{Al}_{0.45} \mathrm{Ta}_{0.08} \mathrm{~N}, \mathrm{Ti}_{0.45} \mathrm{Al}_{0.43} \mathrm{Ta}_{0.15} \mathrm{~N}$, and (b) high Al containing coatings $\mathrm{Ti}_{0.35} \mathrm{Al}_{0.65} \mathrm{~N}, \mathrm{Ti}_{0.32} \mathrm{Al}_{0.60} \mathrm{Ta}_{0.08} \mathrm{~N}$, and $\mathrm{Ti}_{0.30} \mathrm{Al}_{0.54} \mathrm{Ta}_{0.16} \mathrm{~N}$ in inert He atmosphere.

Fig. 4: XRD patterns of (a) medium Al containing coatings $T_{0.51} \mathrm{Al}_{0.49} \mathrm{~N}, \mathrm{Ti}_{0.47} \mathrm{Al}_{0.45} \mathrm{Ta}_{0.08} \mathrm{~N}$, $\mathrm{Ti}_{0.45} \mathrm{Al}_{0.43} \mathrm{Ta}_{0.15} \mathrm{~N}$, and (b) high Al containing coatings $\mathrm{Ti}_{0.35} \mathrm{Al}_{0.65} \mathrm{~N}, \mathrm{Ti}_{0.32} \mathrm{Al}_{0.60} \mathrm{Ta}_{0.08} \mathrm{~N}$, and $\mathrm{Ti}_{0.30} \mathrm{Al}_{0.54} \mathrm{Ta}_{0.16} \mathrm{~N}$ after DSC-TGA to $1600{ }^{\circ} \mathrm{C}$ in inert He atmosphere, Fig. 3.

Fig. 5: Isothermal DSC and TGA measurements of (a) medium Al containing coatings $\mathrm{Ti}_{0.51} \mathrm{Al}_{0.49} \mathrm{~N}, \mathrm{Ti}_{0.47} \mathrm{Al}_{0.45} \mathrm{Ta}_{0.08} \mathrm{~N}, \mathrm{Ti}_{0.45} \mathrm{Al}_{0.43} \mathrm{Ta}_{0.15} \mathrm{~N}$, and (b) high Al containing coatings $\mathrm{Ti}_{0.35} \mathrm{Al}_{0.65} \mathrm{~N}, \mathrm{Ti}_{0.32} \mathrm{Al}_{0.60} \mathrm{Ta}_{0.08} \mathrm{~N}$, and $\mathrm{Ti}_{0.30} \mathrm{Al}_{0.54} \mathrm{Ta}_{0.16} \mathrm{~N}$ in synthetic air at $850{ }^{\circ} \mathrm{C}$. Parabolic fits are indicated by the dashed lines. 
Fig. 6: Isothermal DSC and TGA measurements of (a) medium Al containing coatings $\mathrm{Ti}_{0.51} \mathrm{Al}_{0.49} \mathrm{~N}, \mathrm{Ti}_{0.47} \mathrm{Al}_{0.45} \mathrm{Ta}_{0.08} \mathrm{~N}, \mathrm{Ti}_{0.45} \mathrm{Al}_{0.43} \mathrm{Ta}_{0.15} \mathrm{~N}$, and (b) high Al containing coatings $\mathrm{Ti}_{0.35} \mathrm{Al}_{0.65} \mathrm{~N}, \mathrm{Ti}_{0.32} \mathrm{Al}_{0.60} \mathrm{Ta}_{0.08} \mathrm{~N}$, and $\mathrm{Ti}_{0.30} \mathrm{Al}_{0.54} \mathrm{Ta}_{0.16} \mathrm{~N}$ in synthetic air at $950{ }^{\circ} \mathrm{C}$. Parabolic fits are indicated by the dashed lines.

Fig. 7: XRD patterns of (a) medium Al containing coatings $T_{0.51} \mathrm{Al}_{0.49} \mathrm{~N}, \mathrm{Ti}_{0.47} \mathrm{Al}_{0.45} \mathrm{Ta}_{0.08} \mathrm{~N}$, $\mathrm{Ti}_{0.45} \mathrm{Al}_{0.43} \mathrm{Ta}_{0.15} \mathrm{~N}$, and (b) high Al containing coatings $\mathrm{Ti}_{0.35} \mathrm{Al}_{0.65} \mathrm{~N}, \mathrm{Ti}_{0.32} \mathrm{Al}_{0.60} \mathrm{Ta}_{0.08} \mathrm{~N}$, and $\mathrm{Ti}_{0.30} \mathrm{Al}_{0.54} \mathrm{Ta}_{0.16} \mathrm{~N}$ after DSC-TGA in synthetic air at $850{ }^{\circ} \mathrm{C}$.

Fig 8: XRD patterns of (a) medium Al containing coatings $\operatorname{Ti}_{0.51} \mathrm{Al}_{0.49} \mathrm{~N}, \mathrm{Ti}_{0.47} \mathrm{Al}_{0.45} \mathrm{Ta}_{0.08} \mathrm{~N}$, $\mathrm{Ti}_{0.45} \mathrm{Al}_{0.43} \mathrm{Ta}_{0.15} \mathrm{~N}$, and (b) high Al containing coatings $\mathrm{Ti}_{0.35} \mathrm{Al}_{0.65} \mathrm{~N}, \mathrm{Ti}_{0.32} \mathrm{Al}_{0.60} \mathrm{Ta}_{0.08} \mathrm{~N}$, and $\mathrm{Ti}_{0.30} \mathrm{Al}_{0.54} \mathrm{Ta}_{0.16} \mathrm{~N}$ after DSC-TGA synthetic air at $950{ }^{\circ} \mathrm{C}$.

Fig. 9: SEM fracture cross sections of representative coatings after $20 \mathrm{~h}$ exposure to ambient air at $850{ }^{\circ} \mathrm{C}(\mathrm{a}, \mathrm{b})$ and $950{ }^{\circ} \mathrm{C}(\mathrm{c}, \mathrm{d})$. (a) Fully oxidized $\mathrm{Ti}_{0.35} \mathrm{Al}_{0.65} \mathrm{~N}$. (b) $\mathrm{Ti}_{0.43} \mathrm{Al}_{0.42} \mathrm{Ta}_{0.15} \mathrm{~N}$ with a dense oxide scale on top. (c) $\mathrm{Ti}_{0.30} \mathrm{Al}_{0.54} \mathrm{Ta}_{0.16} \mathrm{~N}$ with a pronounced porous region between the coating and the dense oxide scale on top. (d) $\mathrm{Ti}_{0.32} \mathrm{Al}_{0.60} \mathrm{Ta}_{0.08} \mathrm{~N}$ with a strongly reduced porous region between coating and dense oxide scale.

Fig. 10: XRD patterns of the Ta free coatings after various durations of isothermal DSCTGA in synthetic air at (a) $850{ }^{\circ} \mathrm{C}$ for $\mathrm{Ti}_{0.51} \mathrm{Al}_{0.49} \mathrm{~N}$ and (b) $950{ }^{\circ} \mathrm{C}$ for $\mathrm{Ti}_{0.35} \mathrm{Al}_{0.65} \mathrm{~N}$. For comparison also their XRD patterns in the as deposited state are given. 


\section{Figures}

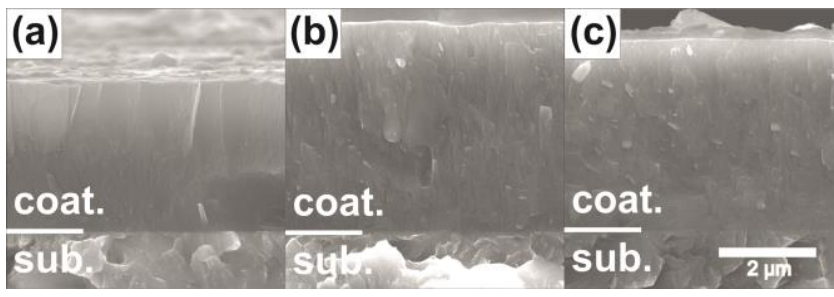

Fig.1

(a)

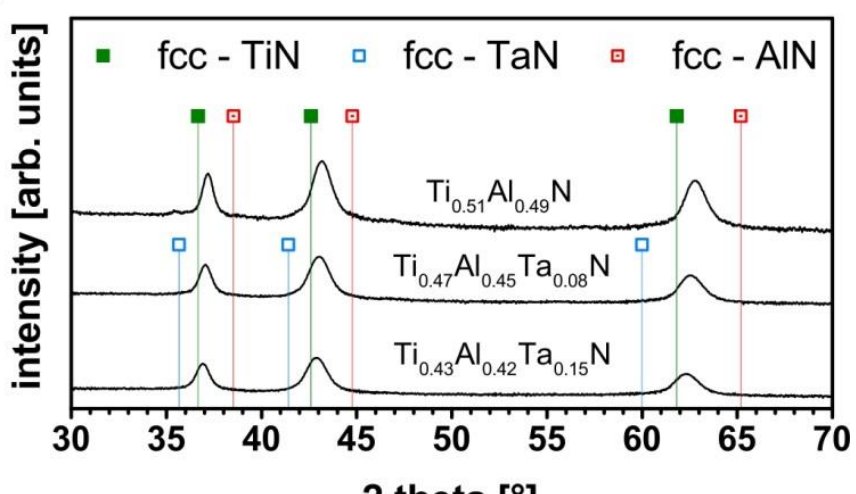

(b)

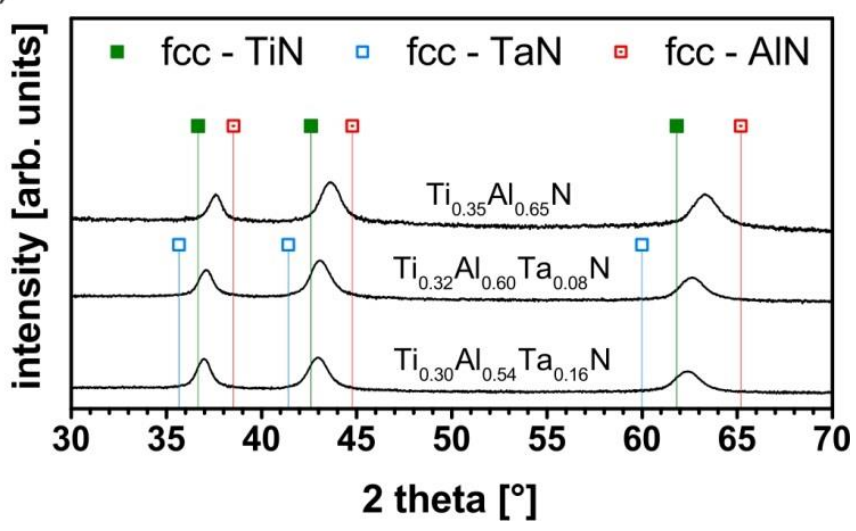

Fig.2 
(a)

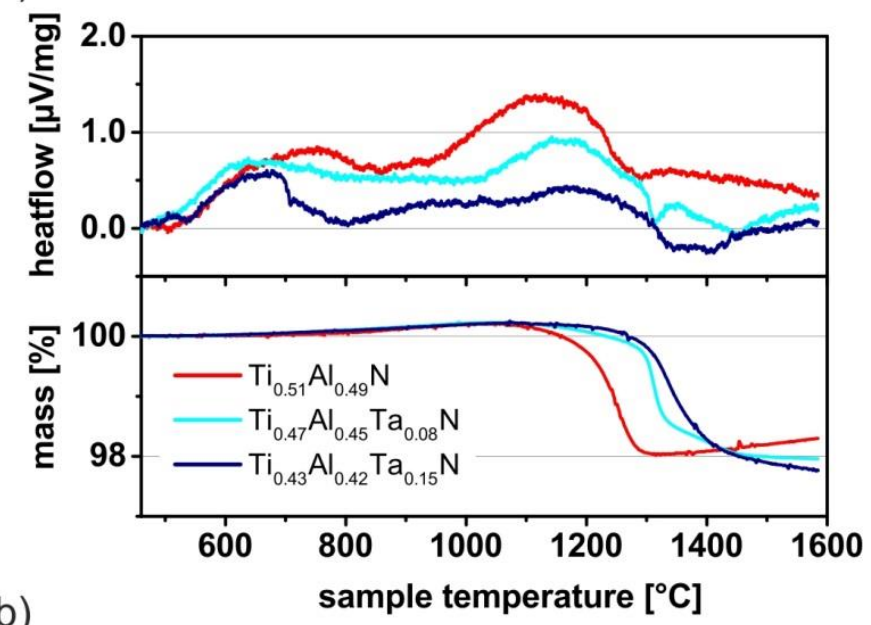

(b)

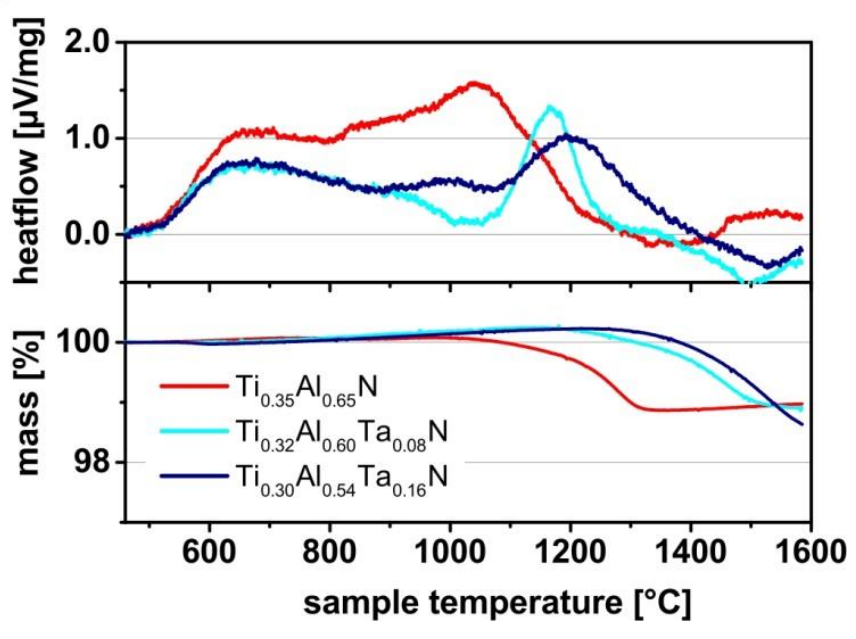

Fig. 3 
(a)

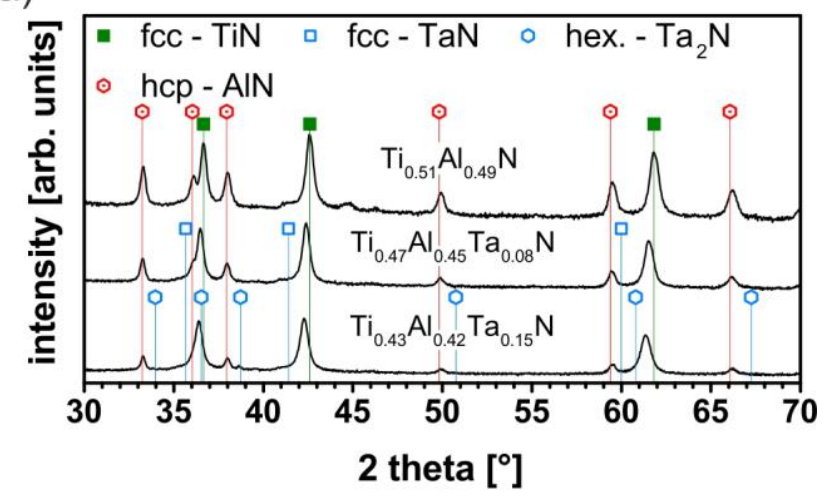

(b)

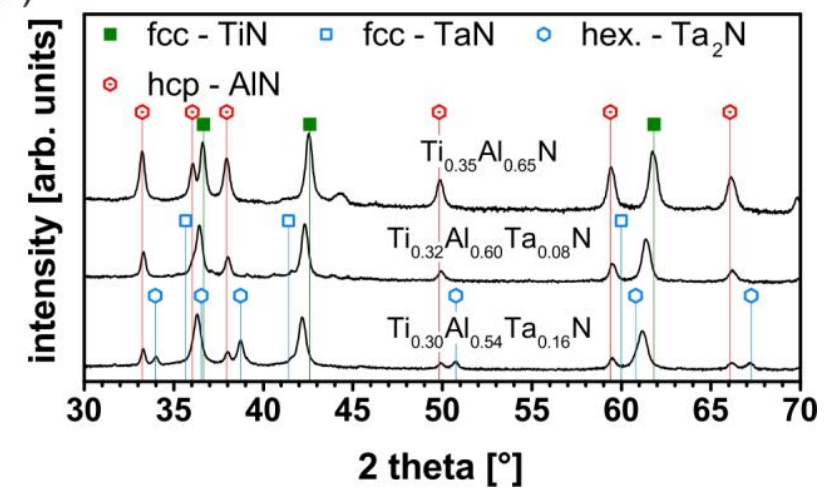

Fig.4 
(a) time [h]

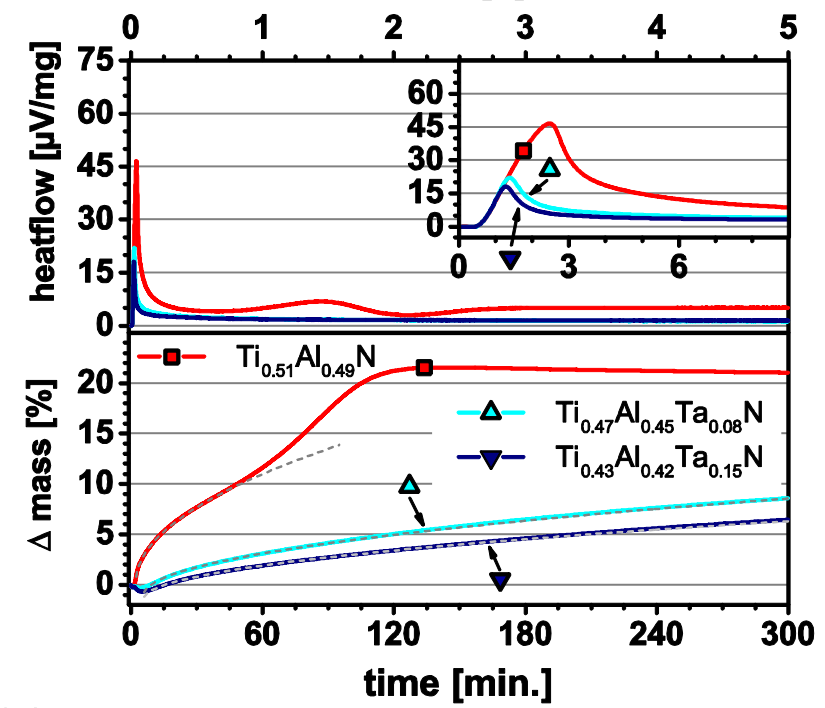

(b)

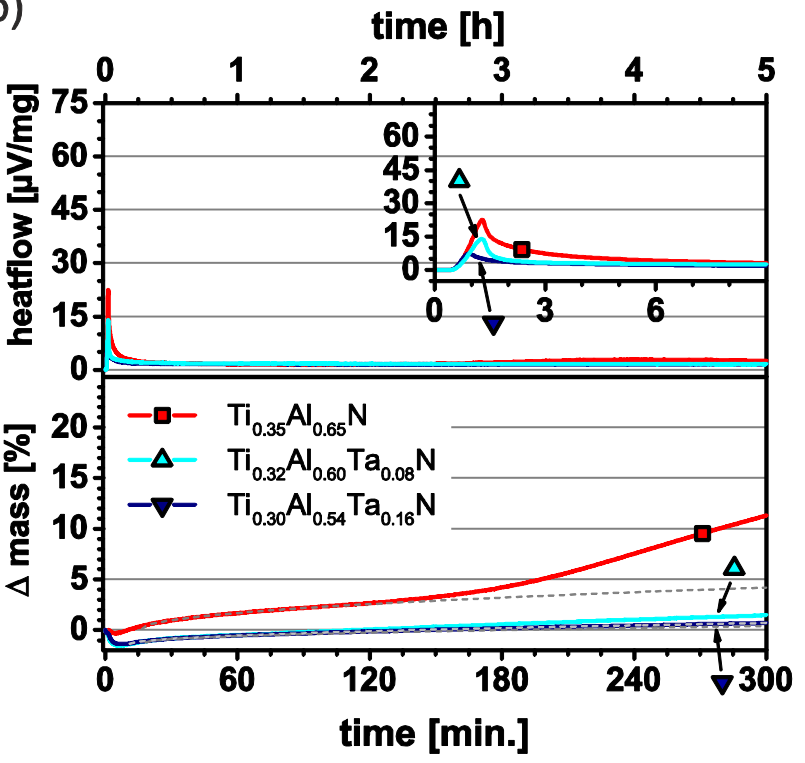

Fig. 5 
(a) time [h]

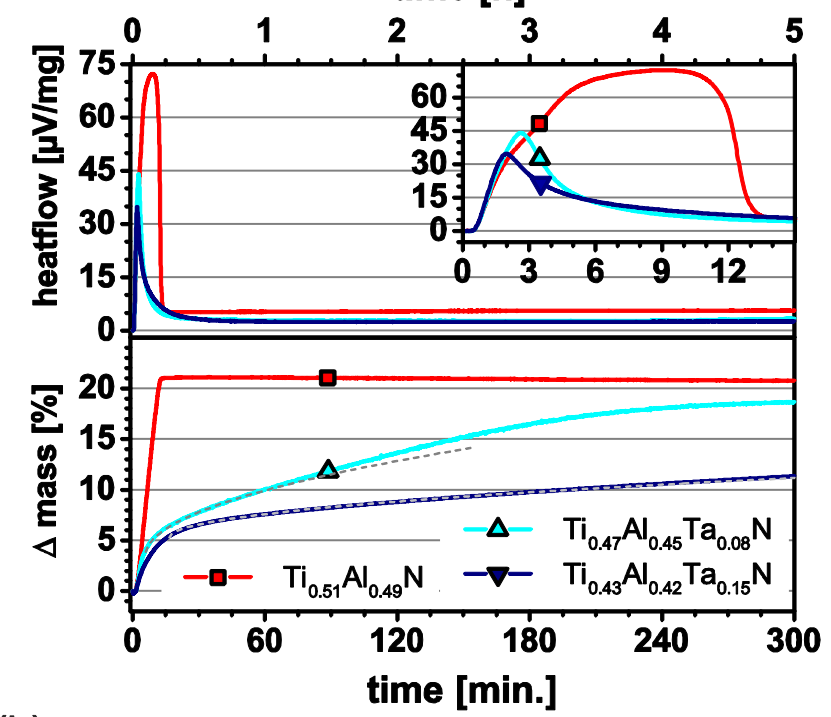

(b) time [h]

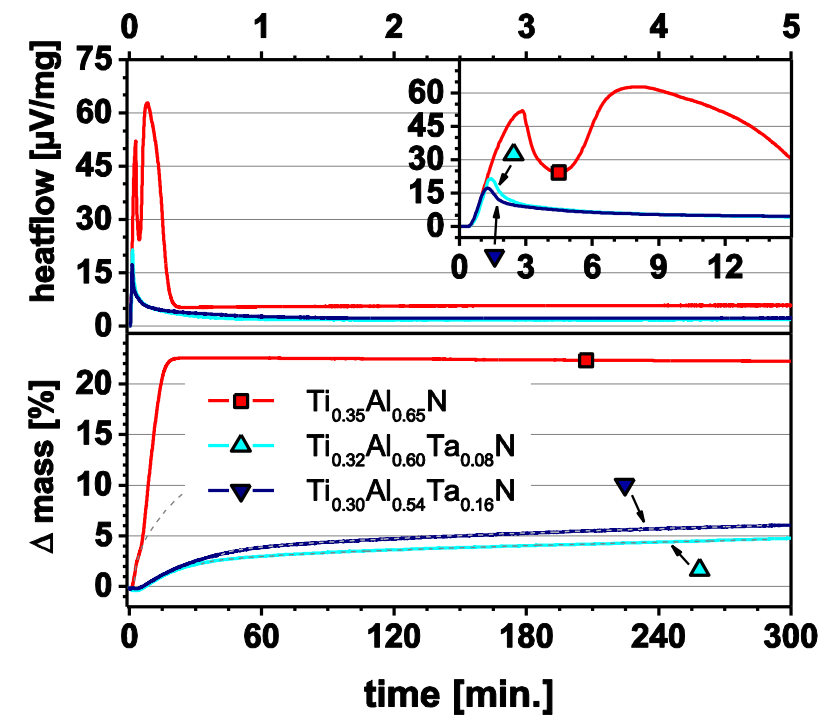

Fig. 6 
(a)

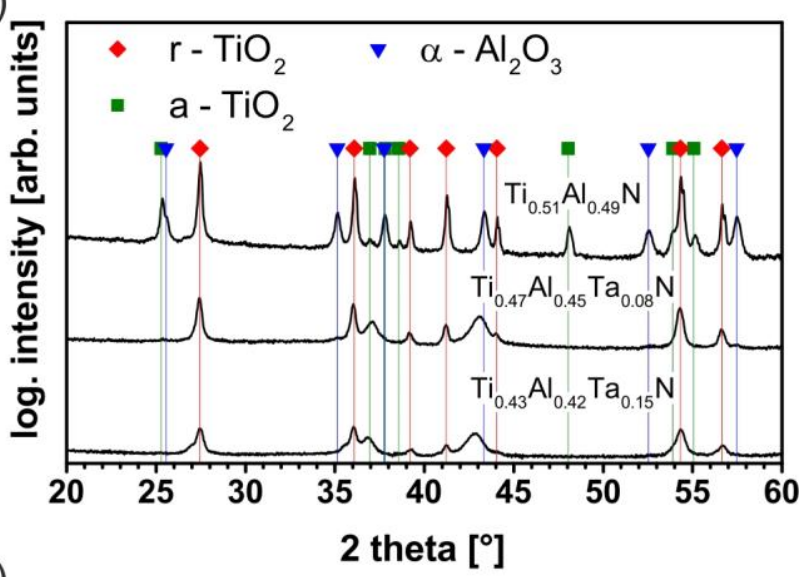

(b)

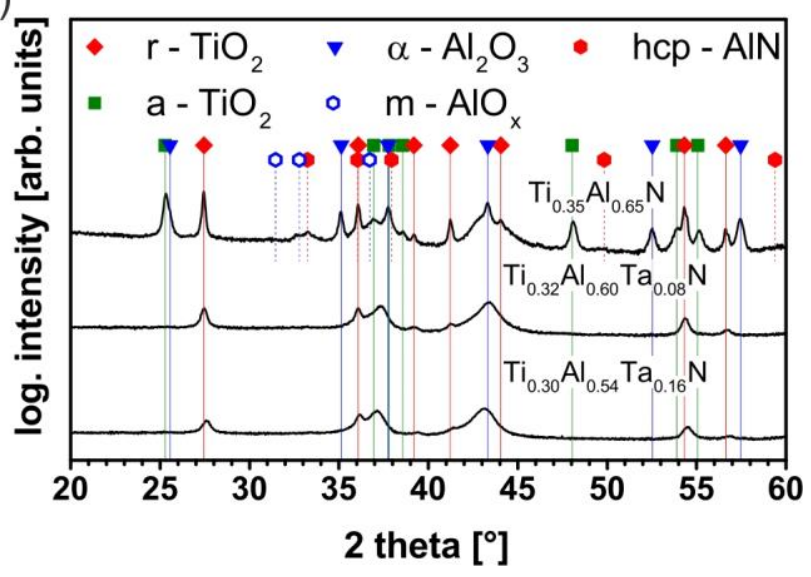

Fig. 7 
(a)

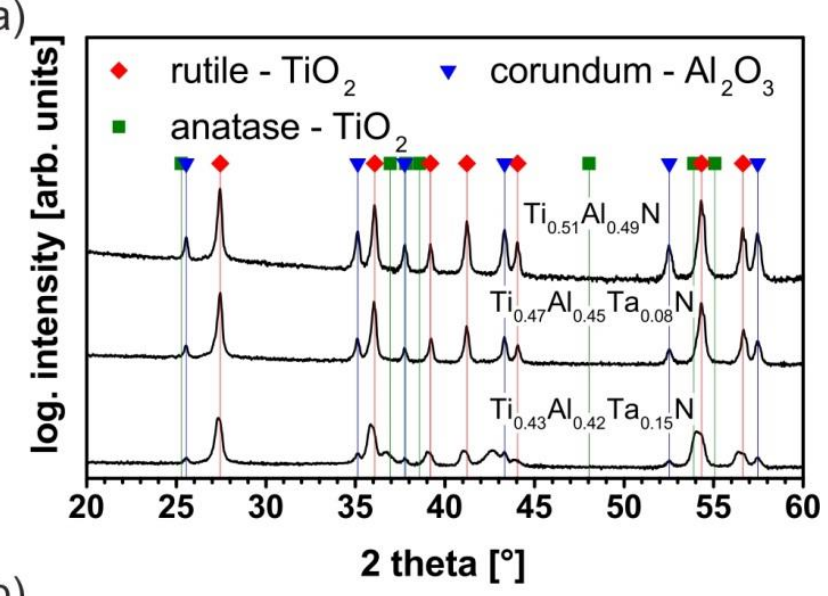

(b)

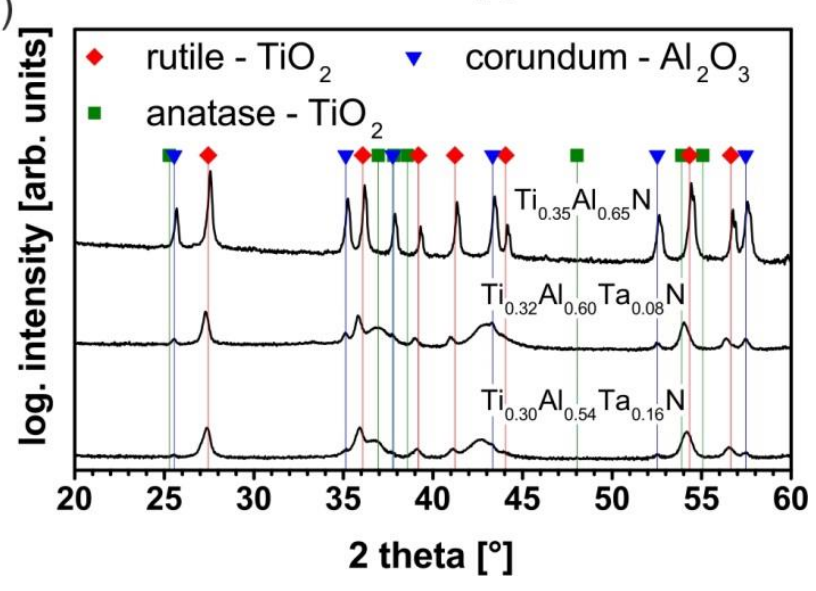

Fig. 8

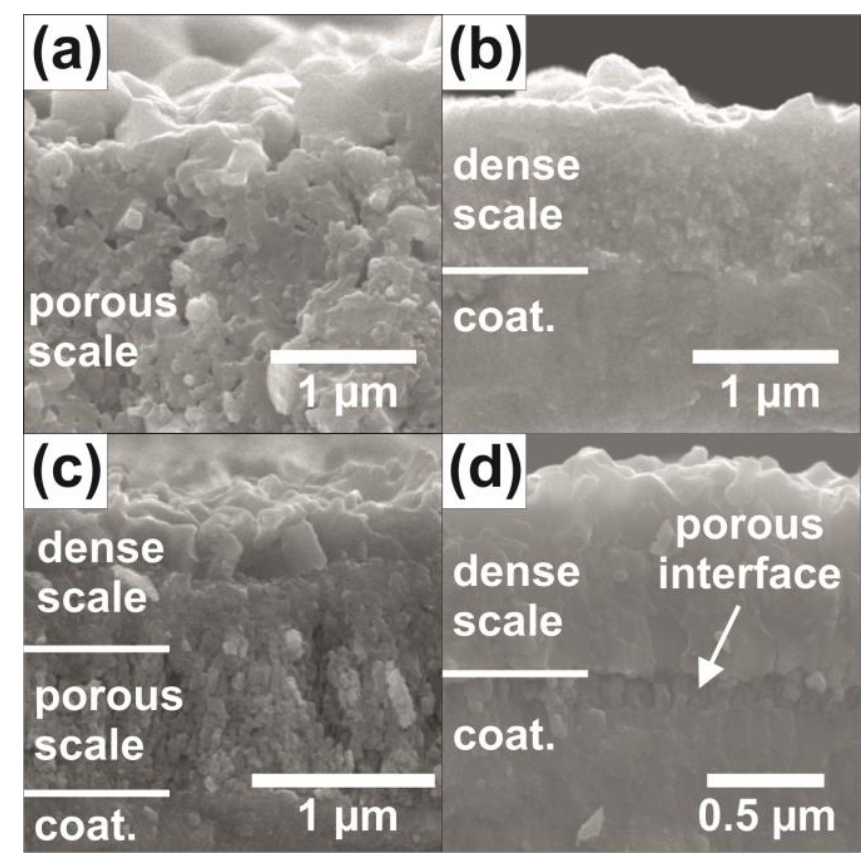

Fig. 9 
(a)

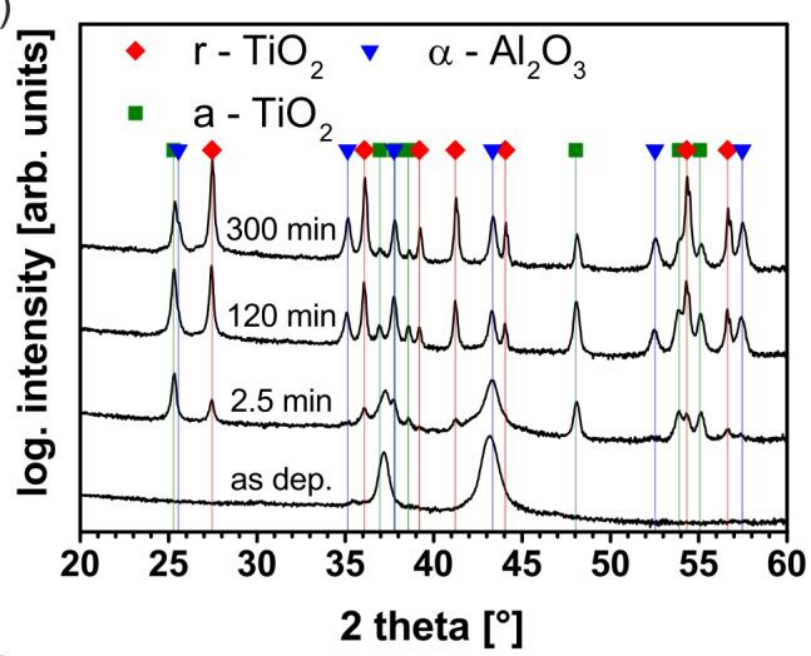

(b)

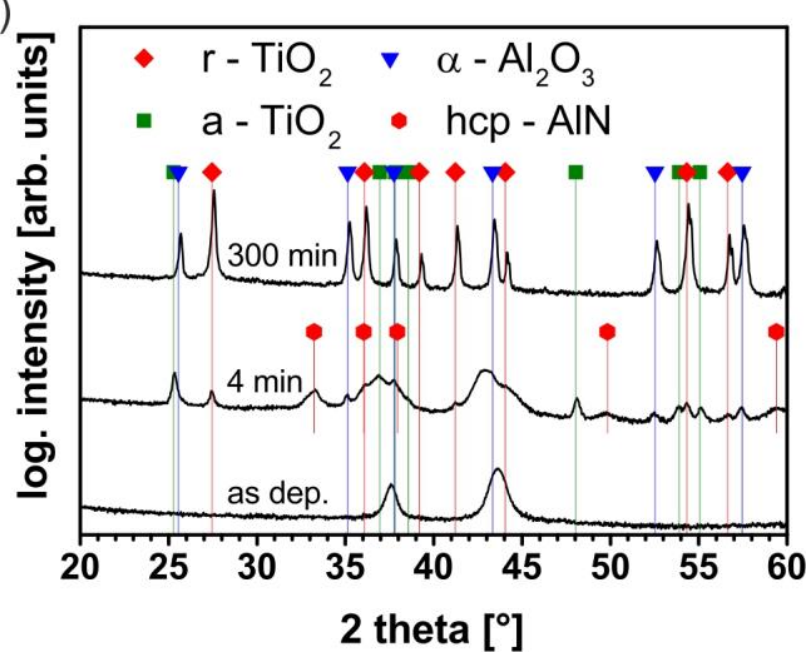

Fig. 10 